\title{
Effectiveness of manual therapies: the UK evidence report
}

\author{
Gert Bronfort ${ }^{1 *}$, Mitch Haas², Roni Evans', Brent Leininger', Jay Triano ${ }^{3,4}$
}

\begin{abstract}
Background: The purpose of this report is to provide a succinct but comprehensive summary of the scientific evidence regarding the effectiveness of manual treatment for the management of a variety of musculoskeletal and non-musculoskeletal conditions.

Methods: The conclusions are based on the results of systematic reviews of randomized clinical trials (RCTs), widely accepted and primarily UK and United States evidence-based clinical guidelines, plus the results of all RCTs not yet included in the first three categories. The strength/quality of the evidence regarding effectiveness was based on an adapted version of the grading system developed by the US Preventive Services Task Force and a study risk of bias assessment tool for the recent RCTs.
\end{abstract}

Results: By September 2009, 26 categories of conditions were located containing RCT evidence for the use of manual therapy: 13 musculoskeletal conditions, four types of chronic headache and nine non-musculoskeletal conditions. We identified 49 recent relevant systematic reviews and 16 evidence-based clinical guidelines plus an additional 46 RCTs not yet included in systematic reviews and guidelines.

Additionally, brief references are made to other effective non-pharmacological, non-invasive physical treatments.

Conclusions: Spinal manipulation/mobilization is effective in adults for: acute, subacute, and chronic low back pain; migraine and cervicogenic headache; cervicogenic dizziness; manipulation/mobilization is effective for several extremity joint conditions; and thoracic manipulation/mobilization is effective for acute/subacute neck pain. The evidence is inconclusive for cervical manipulation/mobilization alone for neck pain of any duration, and for manipulation/mobilization for mid back pain, sciatica, tension-type headache, coccydynia, temporomandibular joint disorders, fibromyalgia, premenstrual syndrome, and pneumonia in older adults. Spinal manipulation is not effective for asthma and dysmenorrhea when compared to sham manipulation, or for Stage 1 hypertension when added to an antihypertensive diet. In children, the evidence is inconclusive regarding the effectiveness for otitis media and enuresis, and it is not effective for infantile colic and asthma when compared to sham manipulation. Massage is effective in adults for chronic low back pain and chronic neck pain. The evidence is inconclusive for knee osteoarthritis, fibromyalgia, myofascial pain syndrome, migraine headache, and premenstrual syndrome. In children, the evidence is inconclusive for asthma and infantile colic.

\section{Background}

The impetus for this report stems from the media debate in the United Kingdom (UK) surrounding the scope of chiropractic care and claims regarding its effectiveness particularly for non-musculoskeletal conditions.

The domain of evidence synthesis is always embedded within the structure of societal values [1]. What constitutes evidence for specific claims is framed by the

\footnotetext{
* Correspondence: gbronfort@nwhealth.edu

'Northwestern Health Sciences University, 2501 W 84th St, Bloomington, MN,
} USA

C 2010 Bronfort et al; licensee BioMed Central Ltd. This is an Open Access article distributed under the terms of the Creative Commons Attribution License (http://creativecommons.org/licenses/by/2.0), which permits unrestricted use, distribution, and reproduction in any medium, provided the original work is properly cited. $[2,3]$. This varies substantially depending on jurisdictional restrictions by country and region. However, over the last several decades a strong international effort has been made to facilitate the systematic incorporation of standardized synthesized clinical research evidence into health care decision making [4].

\section{Evidence-Based Healthcare (EBH)}

EBH is about doing the right things for the right people at the right time [5]. It does so by promoting the 
examination of best available clinical research evidence as the preferred process of decision making where higher quality evidence is available [6]. This reduces the emphasis on unsystematic clinical experience and pathophysiological rationale alone while increasing the likelihood of improving clinical outcomes [7]. The fact that randomized clinical trial (RCT) derived evidence of potentially effective interventions in population studies may not be translated in a straight forward manner to the management of individual cases is widely recognized [8-10]. However, RCTs comprise the body of information best able to meet existing standards for claims of benefit from care delivery. The evidence provided by RCTs constitutes the first line of recommended action for patients and contributes, along with informed patient preference, in guiding care [11]. Practice, as opposed to claims, is inherently interpretative within the context of patient values and ethical defensibility of recommendations $[8,12]$. Indeed, the need to communicate research evidence, or its absence, to patients for truly informed decision-making has become an important area of health care research and clinical practice $[13,14]$.

While some may argue that EBH is more science than art [7], the skill required of clinicians to integrate research evidence, clinical observations, and patient circumstances and preferences is indeed artful [6]. It requires creative, yet informed improvisation and expertise to balance the different types of information and evidence, with each of the pieces playing a greater or lesser role depending on the individual patient and situation [15].

It has become generally accepted that providing evidence-based healthcare will result in better patient outcomes than non-evidence-based healthcare [7]. The debate of whether or not clinicians should embrace an evidence-based approach has become muted. Put simply by one author: "...anyone in medicine today who does not believe in it (EBH) is in the wrong business [7]." Many of the criticisms of EBH were rooted in confusion over what should be done when good evidence is available versus when evidence is weak or nonexistent. From this, misunderstandings and misperceptions arose, including concerns that EBH ignores patient values and preferences and promotes a cookbook approach [16]. When appropriately applied, EBH seeks to empower clinicians so they can develop fact-based independent views regarding healthcare claims and controversies. Importantly, it acknowledges the limitations of using scientific evidence alone to make decisions and emphasizes the importance of patients' values and preferences in clinical decision making [6].

The question is no longer "should" we embrace EBH but "how"? With EBH comes the need for new skills including: efficient literature search strategies and the application of formal rules of evidence in evaluating the clinical literature [6]. It is important to discern the role of the health care provider as an advisor who empowers informed patient decisions. This requires a healthy respect for which scientific literature to use and how to use it. "Cherry-picking" only those studies which support one's views or relying on study designs not appropriate for the question being asked does not promote doing the right thing for the right people at the right time.

Perhaps most critical is the clinician's willingness to change the way they practice when high quality scientific evidence becomes available. It requires flexibility born of intellectual honesty that recognizes one's current clinical practices may not really be in the best interests of the patient. In some cases this will require the abandonment of treatment and diagnostic approaches once believed to be helpful. In other cases it will require the acceptance and training in new methods. The ever-evolving scientific knowledge base demands that clinicians be accepting of the possibility that what is "right" today might not be "right" tomorrow. EBH requires that clinicians' actions are influenced by the evidence [17]. Importantly a willingness to change must accompany the ability to keep up to date with the constant barrage of emerging scientific evidence.

\section{Purpose}

The purpose of this report is to provide a brief and succinct summary of the scientific evidence regarding the effectiveness of manual treatment as a therapeutic option for the management of a variety of musculoskeletal and non-musculoskeletal conditions based on the volume and quality of the evidence. Guidance in translating this evidence to application within clinical practice settings is presented.

\section{Methods}

For the purpose of this report, manual treatment includes spinal and extremity joint manipulation or mobilization, massage and various soft tissue techniques. Manipulation/mobilization under anaesthesia was not included in the report due to the procedure's invasive nature. The conclusions of the report are based on the results of the most recent and most updated (spans the last five to ten years) systematic reviews of RCTs, widely accepted evidence-based clinical guidelines and/or technology assessment reports (primarily from the UK and US if available), and all RCTs not yet included in the first three categories. While critical appraisal of the included reviews and guidelines would be ideal, it is beyond the scope of the present report. The presence of discordance between the conclusions of systematic reviews is explored and described. The conclusions regarding effectiveness are based on comparisons with placebo controls (efficacy) or commonly used treatments which may or may not have been shown to be effective (relative effectiveness), as well 
as comparison to no treatment. The strength/quality of the evidence relating to the efficacy/effectiveness of manual treatment is graded according to an adapted version of the latest grading system developed by the US Preventive Services Task Force (see http://www.ahrq.gov/clinic/ uspstf/grades.htm). The evidence grading system used for this report is a slight modification of the system used in the 2007 Joint Clinical Practice Guideline on low back pain from the American College of Physicians and the American Pain Society [18].

Through a search strategy using the databases MEDLINE (PubMed), Ovid, Mantis, Index to Chiropractic Literature, CINAHL, the specialized databases Cochrane Airways Group trial registry, Cochrane Complementary Medicine Field, and Cochrane Rehabilitation Field, systematic reviews and RCTs as well as evidence-based clinical guidelines were identified. Search restrictions were human subjects, English language, peer-reviewed and indexed journals, and publications before October 2009. In addition, we screened and hand searched reference citations located in the reviewed publications. The description of the search strategy is provided in Additional file 1 (Medline search strategy).

Although findings from studies using a nonrandomized design (for example observational studies, cohort studies, prospective clinical series and case reports) can yield important preliminary evidence, the primary purpose of this report is to summarize the results of studies designed to address efficacy, relative efficacy or relative effectiveness and therefore the evidence base was restricted to RCTs. Pilot RCTs not designed or powered to assess effectiveness, and RCTs designed to test the immediate effect of individual treatment sessions were not part of the evidence base in this report.

The quality of RCTs, which have not been formally quality-assessed within the context of systematic reviews or evidence based guidelines, was assessed by two reviewers with a scale assessing the risk of bias recommended for use in Cochrane systematic reviews of RCTs. Although the Cochrane Collaboration handbook http:// www.cochrane.org/resources/handbook/ discourages that scoring be applied to the risk of bias tool, it does provide suggestion for how trials can be summarized. We have been guided by that suggestion and the adapted evidence grading system used in this report requires that we assess the validity and impact of the latest trial evidence. These additional trials are categorized as higher, moderate, or lower-quality as determined by their attributed risk of bias. For details, see Additional file 2 (The Cochrane Collaboration tool for assessing risk of bias and the rating of the bias for the purpose of this report).

The overall evidence grading system allows the strength of the evidence to be categorized into one of three categories: high quality evidence, moderate quality evidence, and inconclusive (low quality) evidence. The operational definitions of these three categories follow below:

\section{High quality evidence}

The available evidence usually includes consistent results from well-designed, well conducted studies in representative populations which assess the effects on health outcomes.

The evidence is based on at least two consistent higher-quality (low risk of bias) randomized trials. This conclusion is therefore unlikely to be strongly affected by the results of future studies.

\section{Moderate quality evidence}

The available evidence is sufficient to determine the effectiveness relative to health outcomes, but confidence in the estimate is constrained by such factors as:

- The number, size, or quality of individual studies.

- Inconsistency of findings across individual studies.

- Limited generalizability of findings to routine practice.

- Lack of coherence in the chain of evidence.

The evidence is based on at least one higher-quality randomized trial (low risk of bias) with sufficient statistical power, two or more higher-quality (low risk of bias) randomized trials with some inconsistency; at least two consistent, lower-quality randomized trials (moderate risk of bias). As more information becomes available, the magnitude or direction of the observed effect could change, and this change may be large enough to alter the conclusion.

\section{Inconclusive (low quality) evidence}

The available evidence is insufficient to determine effectiveness relative to health outcomes. Evidence is insufficient because of:

- The limited number or power of studies.

- Important flaws in study design or methods (only high risk of bias studies available).

- Unexplained inconsistency between higher-quality trials.

- Gaps in the chain of evidence.

- Findings not generalizable to routine practice.

- Lack of information on important health outcomes

For the purpose of this report a determination was made whether the inconclusive evidence appears favorable or non-favorable or if a direction could even be established (unclear evidence).

Additionally, brief evidence statements are made regarding other non-pharmacological, non-invasive 
physical treatments (for example exercise) and patient educational interventions, shown to be effective and which can be incorporated into evidence-based therapeutic management or co-management strategies in chiropractic practices. These statements are based on conclusions of the most recent and most updated (within last five to ten years) systematic reviews of randomized clinical trials and widely accepted evidencebased clinical guidelines (primarily from the UK and US if available) identified through our search strategy.

\section{Translating Evidence to Action}

Translating evidence requires the communication of salient take-home messages in context of the user's applications [3]. There are two message applications for information derived from this work. First, the criteria for sufficiency of evidence differ depending on the context of the considered actions $[8,19]$. Sufficient evidence to proffer claims of effectiveness is defined within the sociopolitical context [20] of ethics and regulation. Separate is the second application of evidence to inform decision making for individual patients. Where there is strength of evidence and the risk of bias is small, the preferred choices require little clinical judgment. Alternatively, when evidence is uncertain and/or there is higher risk of bias, then greater emphasis is placed on the patient as an active participant [11]. This requires the clinician to effectively communicate research evidence to patients while assisting their informed decision-making [19].

In summary, the information derived within this report are directed to two applications 1) the determination of supportable public claims of treatment effectiveness for chiropractic care within the context of social values; and 2) the use of evidence information as a basis for individualized health care recommendations using the hierarchy of evidence (Figure 1).

\section{Results}

By September 2009, 26 categories of conditions were located containing RCT evidence for the use of manual therapy: 13 musculoskeletal conditions, four types of chronic headache and nine non-musculoskeletal conditions (Figure 2). We identified 49 recent relevant systematic reviews and 16 evidence-based clinical guidelines plus an additional 46 RCTs not yet included within the identified systematic reviews and guidelines. A number of other non-invasive physical treatments and patient education with evidence of effectiveness were identified including exercise, yoga, orthoses, braces, acupuncture, heat, electromagnetic field therapy, TENS, laser therapy, cognitive behavioral therapy and relaxation. The report presents the evidence of effectiveness or ineffectiveness of manual therapy as evidence summary statements at the end of the section for each condition and in briefer summary form in Figures 3, 4, 5, 6, and 7. Additionally, definitions and brief diagnostic criteria for the conditions reviewed are provided. Diagnostic imaging for many conditions is indicated by the presence of "red flags" suggestive of serious pathology. Red flags may vary depending on the condition under consideration, but typically include fractures, trauma, metabolic disorders, infection, metastatic disease, and other pathological disease processes contraindicative to manual therapy.

\section{Non-specific Low Back Pain (LBP) Definition}

Non-specific LBP is defined as soreness, tension, and/or stiffness in the lower back region for which it is not possible to identify a specific cause of pain [21].

\section{Diagnosis}

Diagnosis of non-specific LBP is derived from the patient's history with an unremarkable neurological exam and no indicators of potentially serious pathology. Imaging is only indicated in patients with a positive neurological exam or presence of a "red flag" [21-24].

\section{Evidence base for manual treatment Systematic reviews (most recent)}

Since 2004, five systematic reviews made a comprehensive evaluation of the benefit of spinal manipulation for non-specific LBP [25-30]. Approximately 70 RCTs were summarized. The reviews found that spinal manipulation was superior to sham intervention and similar in effect to other commonly used efficacious therapies such as usual care, exercise, or back school. For sciatica/ radiating leg pain, three reviews $[18,25,27]$ found manipulation to have limited evidence. Furlan et al [30] concluded massage is beneficial for patients with subacute and chronic non-specific low-back pain based on a review of 13 RCTs.

\section{Evidence-based clinical guidelines}

Since 2006, four guidelines make recommendations regarding the benefits of manual therapies for the care of LBP: NICE [21,31], The American College of Physicians/American Pain Society [18,22], European guidelines for chronic LBP [23], and European guidelines for acute LBP [24]. The number of RCTs included within the various guidelines varied considerably based on their scope, with the NICE guidelines including eight trials and The American College of Physicians/American Pain Society guidelines including approximately 70 trials. These guidelines in aggregate recommend spinal manipulation/mobilization as an effective treatment for acute, subacute, and chronic LBP. Massage is also recommended for the treatment of subacute and chronic LBP. 


\begin{tabular}{|c|c|}
\hline Level of Evidence* & Actions Supported \\
\hline $\begin{array}{l}\text { High and Moderate quality } \\
\text { POSITIVE evidence }\end{array}$ & $\begin{array}{l}\text { - Supports public favor able claims regarding } \\
\text { effectiveness } \\
\text { - Advise patients that this is an effective treatment } \\
\text { choice }\end{array}$ \\
\hline $\begin{array}{l}\text { INCONCLUSIVE, but } \\
\text { favorable evidence }\end{array}$ & $\begin{array}{l}\text { - Does not support any public claims regarding } \\
\text { effectiveness } \\
\text { - Recommend effective alternative if available } \\
\text { - Advise patients that this is a treatment option in } \\
\text { the absence of an effective alternative }\end{array}$ \\
\hline $\begin{array}{c}\text { INCONCLUSIVE, and } \\
\text { unclear direction of evidence }\end{array}$ & $\begin{array}{l}\text { - Recommend effective alternative if available } \\
\text { - Advise patients that the effectiveness of this } \\
\text { treatment option has not been established }\end{array}$ \\
\hline $\begin{array}{l}\text { INCONCLUSIVE, but non- } \\
\text { favorable evidence }\end{array}$ & $\begin{array}{l}\text { - Advise patients that this treatment option is } \\
\text { unlikely to be effective } \\
\text { - Recommend effective alternative if available }\end{array}$ \\
\hline $\begin{array}{l}\text { High and Moderate quality } \\
\text { NEGATIVE evidence }\end{array}$ & $\begin{array}{l}\text { - Advise patients AGAINST this as a treatment } \\
\text { option } \\
\text { - Recommend effective alternative if available }\end{array}$ \\
\hline
\end{tabular}

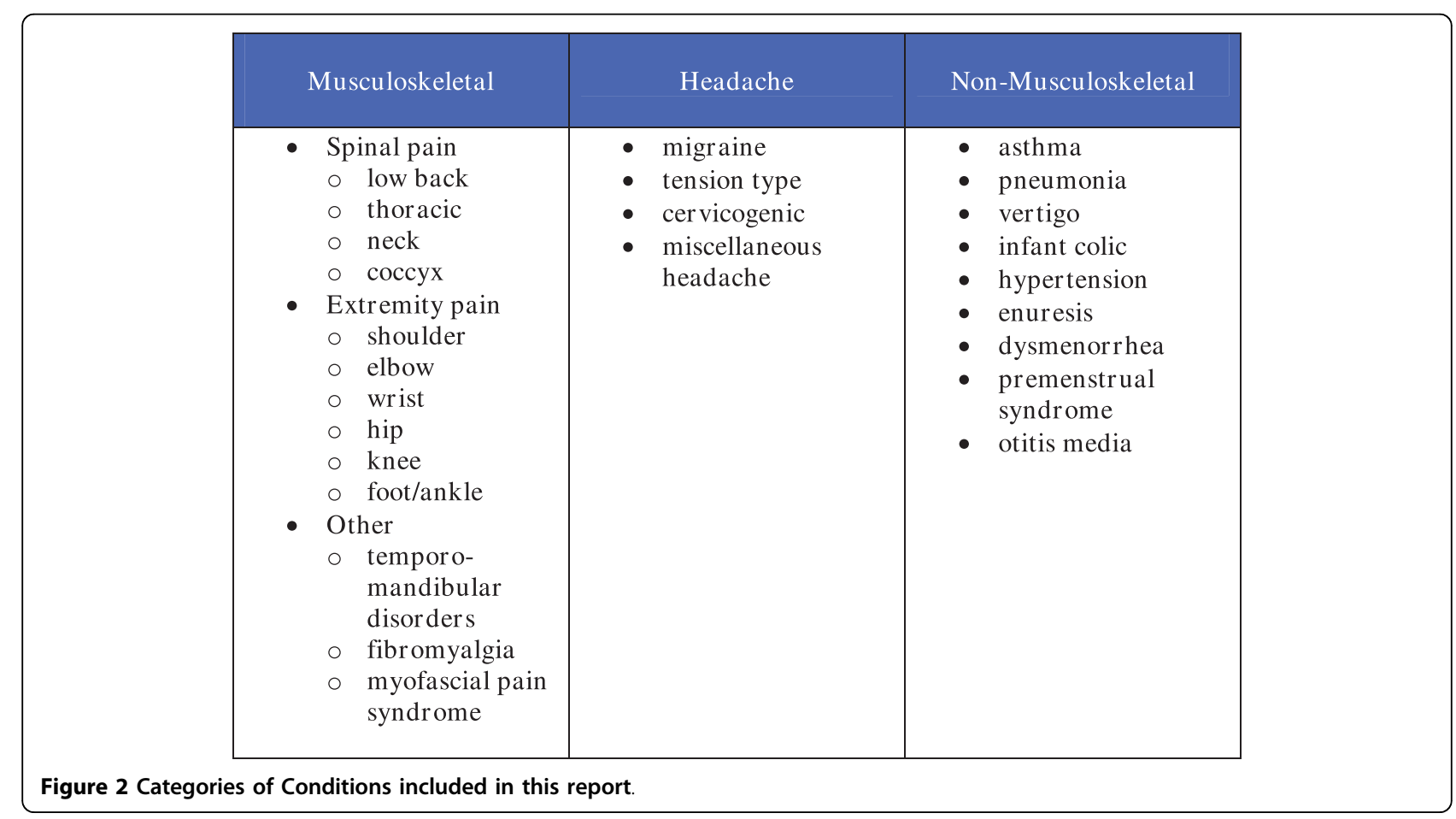




\begin{tabular}{|c|c|c|c|c|}
\hline Spinal Conditions & Intervention & \multicolumn{3}{|c|}{ Evidence } \\
\hline & & Inconclusive & Moderate & High \\
\hline Acute Low Back Pain & $\begin{array}{l}\text { Spinal manipulation } \\
\text { /mobilization }\end{array}$ & & positive & \\
\hline $\begin{array}{l}\text { Chronic Low Back } \\
\text { Pain }\end{array}$ & $\begin{array}{l}\text { Spinal manipulation } \\
\text { /mobilization }\end{array}$ & & & positive \\
\hline $\begin{array}{l}\text { Chronic Low Back } \\
\text { Pain }\end{array}$ & Massage & & positive & \\
\hline $\begin{array}{l}\text { Chronic Low Back } \\
\text { Pain }\end{array}$ & $\begin{array}{l}\text { Foot reflexology } \\
\text { added to usual } \\
\text { medical care }\end{array}$ & non-favorable & & \\
\hline $\begin{array}{l}\text { Sciatica/ Radiating } \\
\text { Leg Pain }\end{array}$ & $\begin{array}{l}\text { Spinal manipulation } \\
\text { /mobilization }\end{array}$ & favorable & & \\
\hline Coccydynia & Spinal manipulation & favorable & & \\
\hline Mid Back Pain & Spinal manipulation & favorable & & \\
\hline $\begin{array}{l}\text { Acute/subacute Neck } \\
\text { Pain }\end{array}$ & $\begin{array}{l}\text { Thoracic spinal } \\
\text { manipulation/ } \\
\text { mobilization }\end{array}$ & & positive & \\
\hline $\begin{array}{l}\text { Acute Whiplash- } \\
\text { Associated Disorders }\end{array}$ & $\begin{array}{l}\text { Mobilization with } \\
\text { exercise }\end{array}$ & & positive & \\
\hline Chronic Neck Pain & $\begin{array}{l}\text { Spinal manipulation } \\
\text { /mobilization with } \\
\text { exercise }\end{array}$ & & positive & \\
\hline $\begin{array}{l}\text { Neck Pain of any } \\
\text { duration }\end{array}$ & $\begin{array}{l}\text { Cervical spinal } \\
\text { manipulation/ } \\
\text { mobilization alone }\end{array}$ & favorable & & \\
\hline Chronic Neck Pain & Massage & & positive & \\
\hline
\end{tabular}

Figure 3 Evidence Summary - Adults - Spinal Conditions.

Recent randomized clinical trials not included in above Hallegraeff et al [32] compared a regimen of spinal manipulation plus standard physical therapy to standard physical therapy for acute LBP. Overall there were no differences between groups for pain and disability post treatment. Prediction rules may have affected outcomes. This study had a high risk of bias.

Rasmussen et al [33] found patients receiving extension exercise or receiving extension exercise plus spinal manipulation experienced a decrease in chronic LBP, but no differences were noted between groups. This study had a high risk of bias.

Little et al [34] found Alexander technique, exercise, and massage were all superior to control (normal care) at three months for chronic LBP and disability. This study had a moderate risk of bias.

Wilkey et al [35] found chiropractic management was superior to NHS pain clinic management for chronic LBP at eight weeks for pain and disability outcomes. This study had a high risk of bias. 


\begin{tabular}{|c|c|c|c|c|}
\hline \multirow[t]{2}{*}{ Extremity Conditions } & Inter vention & \multicolumn{3}{|c|}{ Evidence } \\
\hline & & Inconclusive & Moderate & High \\
\hline $\begin{array}{l}\text { Shoulder Girdle Pain/ } \\
\text { Dysfunction }\end{array}$ & $\begin{array}{l}\text { Manipulation/ } \\
\text { mobilization }\end{array}$ & & positive & \\
\hline Rotator Cuff Pain & $\begin{array}{l}\text { Manipulation/ } \\
\text { mobilization }\end{array}$ & favorable & & \\
\hline Shoulder Pain & Massage & favorable & & \\
\hline Adhesive Capsulitis & $\begin{array}{l}\text { High-grade } \\
\text { mobilization }\end{array}$ & & positive & \\
\hline $\begin{array}{l}\text { Tennis Elbow (Lateral } \\
\text { Epicondylitis) }\end{array}$ & Manipulation & non-favorable & & \\
\hline $\begin{array}{l}\text { Tennis Elbow (Lateral } \\
\text { Epicondylitis) }\end{array}$ & $\begin{array}{l}\text { Manual tender } \\
\text { point therapy }\end{array}$ & favorable & & \\
\hline $\begin{array}{l}\text { Tennis Elbow (Lateral } \\
\text { Epicondylitis) }\end{array}$ & $\begin{array}{l}\text { Mobilization with } \\
\text { exercise }\end{array}$ & & positive & \\
\hline $\begin{array}{l}\text { Carpal Tunnel } \\
\text { Syndrome }\end{array}$ & $\begin{array}{l}\text { Manipulation/ } \\
\text { mobilization }\end{array}$ & favorable & & \\
\hline Hip Osteoarthritis & $\begin{array}{l}\text { Manipulation/ } \\
\text { mobilization }\end{array}$ & & positive & \\
\hline $\begin{array}{l}\text { Hip Arthroplasty } \\
\text { Rehabilitation }\end{array}$ & $\begin{array}{l}\text { Osteopathic } \\
\text { manipulative } \\
\text { therapy (OMT) }\end{array}$ & non-favorable & & \\
\hline Knee Osteoarthritis & $\begin{array}{l}\text { Manipulation/ } \\
\text { mobilization with } \\
\text { exercise }\end{array}$ & & positive & \\
\hline $\begin{array}{l}\text { Patellofemoral Pain } \\
\text { Syndrome }\end{array}$ & $\begin{array}{l}\text { Manipulation/ } \\
\text { mobilization with } \\
\text { exercise }\end{array}$ & & positive & \\
\hline $\begin{array}{l}\text { Knee Arthroplasty } \\
\text { Rehabilitation }\end{array}$ & OMT & non-favorable & & \\
\hline Knee Osteoarthritis & Massage & favorable & & \\
\hline Ankle Sprains & $\begin{array}{l}\text { Manipulation/ } \\
\text { mobilization }\end{array}$ & favorable & & \\
\hline $\begin{array}{l}\text { Ankle Fracture } \\
\text { Rehabilitation }\end{array}$ & Mobilization & & negative & \\
\hline Plantar Fasciitis & $\begin{array}{l}\text { Manipulation/ } \\
\text { mobilization with } \\
\text { exercise }\end{array}$ & & positive & \\
\hline Morton's Neuroma & $\begin{array}{l}\text { Manipulation/ } \\
\text { mobilization }\end{array}$ & favorable & & \\
\hline Hallux Limitus & $\begin{array}{l}\text { Manipulation/ } \\
\text { mobilization }\end{array}$ & favorable & & \\
\hline $\begin{array}{l}\text { Hallux Abducto } \\
\text { Valgus }\end{array}$ & $\begin{array}{l}\text { Manipulation/ } \\
\text { mobilization }\end{array}$ & favorable & & \\
\hline
\end{tabular}




\begin{tabular}{|c|c|c|c|c|}
\hline \multirow{2}{*}{$\begin{array}{l}\text { Headache and other } \\
\text { Conditions }\end{array}$} & Inter vention & \multicolumn{3}{|c|}{ Evidence } \\
\hline & & Inconclusive & Moderate & High \\
\hline Migraine Headache & Spinal manipulation & & positive & \\
\hline Migraine Headache & Massage alone & favorable & & \\
\hline Tension type headache & $\begin{array}{l}\text { Spinal } \\
\text { Manipulation }\end{array}$ & unclear & & \\
\hline $\begin{array}{l}\text { Cervicogenic } \\
\text { Headache }\end{array}$ & $\begin{array}{l}\text { Spinal } \\
\text { Manipulation }\end{array}$ & & positive & \\
\hline $\begin{array}{l}\text { Cervicogenic } \\
\text { Headache }\end{array}$ & $\begin{array}{l}\text { Self-mobilizing } \\
\text { Apophyseal Glides }\end{array}$ & & positive & \\
\hline $\begin{array}{l}\text { Cervicogenic } \\
\text { Headache }\end{array}$ & $\begin{array}{l}\text { Friction massage } \\
\text { and trigger points }\end{array}$ & non-favorable & & \\
\hline $\begin{array}{l}\text { Cervicogenic } \\
\text { Headache }\end{array}$ & Mobilization & unclear & & \\
\hline $\begin{array}{l}\text { Miscellaneous } \\
\text { Headache }\end{array}$ & Mobilization & favorable & & \\
\hline $\begin{array}{l}\text { Cervicogenic } \\
\text { dizziness }\end{array}$ & $\begin{array}{l}\text { Self-mobilizing } \\
\text { Apophyseal Glides }\end{array}$ & & positive & \\
\hline $\begin{array}{l}\text { Temporo-mandibular } \\
\text { joint dysfunction }\end{array}$ & $\begin{array}{l}\text { Mobilization/ } \\
\text { massage }\end{array}$ & favorable & & \\
\hline Fibromyalgia & Massage & favorable & & \\
\hline Fibromyalgia & Spinal manipulation & unclear & & \\
\hline Fibromyalgia & $\begin{array}{l}\text { Manual lymph } \\
\text { drainage }\end{array}$ & favorable & & \\
\hline $\begin{array}{l}\text { Myofascial Pain } \\
\text { Syndrome }\end{array}$ & Massage & favorable & & \\
\hline
\end{tabular}

Figure 5 Evidence Summary - Adults - Headache and Other Conditions

Bogefeldt et al [36] found manual therapy plus advice to stay active was more effective than advice to stay active alone for reducing sick leave and improving return to work at 10 weeks for acute LBP. No differences between the groups were noted at two years. This study had a low risk of bias.

Hancock et al [37] found spinal mobilization in addition to medical care was no more effective than medical care alone at reducing the number of days until full recovery for acute LBP. This study had a low risk of bias.

Ferreira et al [38] found spinal manipulation was superior to general exercise for function and perceived effect at eight weeks in chronic LBP patients, but no differences were noted between groups at six and 12 months. This study had a moderate risk of bias.

Eisenberg et al [39] found that choice of complementary therapies (including chiropractic care) in addition to usual care was no different from usual care in bothersomeness and disability for care of acute LBP. The trial did not report findings for any individual manual therapy. This study had a low risk of bias.

Hondras et al [40] found lumbar flexion-distraction was superior to minimal medical care at 3,6,9,12, and 24 weeks for disability related to subacute or chronic LBP, but spinal manipulation was superior to minimal medical care only at three weeks. No differences between spinal manipulation and flexion-distraction were noted for any reported outcomes. Global perceived improvement was superior at 12 and 24 weeks for both manual therapies compared to minimal medical care. This study had a low risk of bias.

Mohseni-Bandpei et al [41] showed that patients receiving manipulation/exercise for chronic LBP reported greater improvement compared with those receiving ultrasound/exercise at both the end of the 


\begin{tabular}{|c|c|c|c|c|}
\hline \multirow{2}{*}{$\begin{array}{c}\text { Non-Musculoskeletal } \\
\text { Conditions }\end{array}$} & Intervention & \multicolumn{3}{|c|}{ Evidence } \\
\hline & & Inconclusive & Moderate & High \\
\hline Asthma & Spinal manipulation & & negative & \\
\hline Asthma & Foot reflexology & non-favorable & & \\
\hline $\begin{array}{l}\text { Pneumonia in } \\
\text { Older Adults }\end{array}$ & $\begin{array}{l}\text { Osteopathic } \\
\text { manipulative } \\
\text { therapy }\end{array}$ & favorable & & \\
\hline $\begin{array}{l}\text { Cervicogenic } \\
\text { dizziness }\end{array}$ & Mobilization & & positive & \\
\hline $\begin{array}{l}\text { Stage } 1 \\
\text { Hypertension }\end{array}$ & $\begin{array}{l}\text { Spinal manipulation } \\
\text { added to diet }\end{array}$ & & negative & \\
\hline Hypertension & $\begin{array}{l}\text { Instrument } \\
\text { assisted spinal } \\
\text { manipulation }\end{array}$ & unclear & & \\
\hline Stage 1 Hypertension & $\begin{array}{l}\text { Upper Cervical } \\
\text { (NUCCA) Spinal } \\
\text { manipulation }\end{array}$ & favorable & & \\
\hline Dysmenorrhea & $\begin{array}{l}\text { Spinal } \\
\text { manipulation }\end{array}$ & & negative & \\
\hline $\begin{array}{l}\text { Premenstrual } \\
\text { syndrome }\end{array}$ & $\begin{array}{l}\text { Spinal } \\
\text { manipulation }\end{array}$ & unclear & & \\
\hline $\begin{array}{l}\text { Premenstrual } \\
\text { syndrome }\end{array}$ & Massage & favorable & & \\
\hline $\begin{array}{l}\text { Premenstrual } \\
\text { syndrome }\end{array}$ & Reflexology & favorable & & \\
\hline
\end{tabular}

Figure 6 Evidence Summary - Adults - Non-Musculoskeletal Conditions.

treatment period and at 6-month follow-up. The study had a high risk of bias.

Beyerman et al [42] evaluated the efficacy of chiropractic spinal manipulation, manual flexion/distraction, and hot pack application for the treatment of LBP of mixed duration from osteoarthritis (OA) compared with moist heat alone. The spinal manipulation group reported more and faster short term improvement in pain and range of motion. The study had a high risk of bias.

Poole et al [43] showed that adding either foot reflexology or relaxation training to usual medical care in patients with chronic LBP is no more effective than usual medical care alone in either the short or long term. The study had a moderate risk of bias.

Zaproudina et al [44] found no differences between groups (bonesetting versus exercise plus massage) at one month or one year for pain or disability. The global assessment score of improvement was superior for the bonesetting group at one month. This study had a high risk of bias.

\section{Evidence Summary (See Figure 3)}

- High quality evidence that spinal manipulation/ mobilization is an effective treatment option for subacute and chronic LBP in adults [18,21,23].

- Moderate quality evidence that spinal manipulation/mobilization is an effective treatment option for subacute and chronic LBP in older adults [40].

- Moderate quality evidence that spinal manipulation/mobilization is an effective treatment option for acute LBP in adults [18,24].

- Moderate evidence that adding spinal mobilization to medical care does not improve outcomes for acute LBP in adults [37].

- Moderate quality evidence that massage is an effective treatment for subacute and chronic LBP in adults $[22,30]$. 


\begin{tabular}{|l|l|l|l|l|}
\hline \multirow{2}{*}{$\begin{array}{c}\text { Non-Musculoskeletal } \\
\text { Conditions }\end{array}$} & \multicolumn{1}{|c|}{ Intervention } & \multicolumn{2}{c|}{ Evidence } \\
& & Inconclusive & Moder ate & High \\
\hline Asthma & Spinal manipulation & & negative & \\
\hline Asthma & $\begin{array}{l}\text { Osteopathic } \\
\text { manipulative } \\
\text { therapy(OMT) }\end{array}$ & favorable & & \\
\hline Colic & Massage & unclear & & \\
\hline Colic & Spinal manipulation & & negative & \\
\hline Colic & Cranial OMT & favorable & & \\
\hline Nocturnal Enuresis & Spinal manipulation & favorable & & \\
\hline Otitis media & OMT & unclear & & \\
\hline
\end{tabular}

Figure 7 Evidence Summary - Pediatrics - Non-Musculoskeletal Conditions

- Inconclusive evidence in a favorable direction regarding the use of manipulation for sciatica/ radiating leg pain $[22,25,27]$.

- Inconclusive evidence in a non-favorable direction regarding the addition of foot reflexology to usual medical care for chronic LBP [43].

Other effective non-invasive physical treatments or patient education

Advice to stay active, interdisciplinary rehabilitation, exercise therapy, acupuncture, yoga, cognitive-behavioral therapy, or progressive relaxation for chronic LBP and superficial heat for acute LBP $[18,22]$.

\section{Non-specific mid back pain \\ Definition}

Non-specific thoracic spine pain is defined as soreness, tension, and/or stiffness in the thoracic spine region for which it is not possible to identify a specific cause of pain [45].

\section{Diagnosis}

Diagnosis of non-specific thoracic spine pain is derived from the patient's history with an unremarkable neurological exam and no indicators of potentially serious pathology. Imaging is only indicated in patients with a positive neurological exam or presence of a "red flag" $[45,46]$.

\section{Evidence base for manual treatment}

\section{Systematic reviews (most recent)}

No systematic reviews addressing the role of manual therapy in thoracic spine pain that included randomized clinical trials were located.

\section{Evidence-based clinical guidelines}

The Australian acute musculoskeletal pain guidelines group concludes there is evidence from one small pilot study [47] that spinal manipulation is effective compared to placebo for thoracic spine pain.

Recent randomized clinical trials not included in above Multiple randomized clinical trials investigating the use of thoracic spinal manipulation were located [48-53]; however, most of the trials assessed the effectiveness of thoracic manipulation for neck or shoulder pain.

\section{Evidence Summary (See Figure 3)}

- Inconclusive evidence in a favorable direction regarding the use of spinal manipulation for mid back pain [47].

Other effective non-invasive physical treatments or patient education

None

\section{Mechanical neck pain \\ Definition}

Mechanical neck pain is defined as pain in the anatomic region of the neck for which it is not possible to identify a specific pathological cause of pain [54,55]. It generally includes neck pain, with or without pain in the upper limbs which may or may not interfere with activities of daily living (Grades I and II). Signs and symptoms indicating significant neurologic compromise (Grade III) or major structural pathology (Grade IV including fracture, vertebral dislocation, neoplasm, etc.) are NOT included.

\section{Diagnosis}

Diagnosis of mechanical neck pain is derived from the patient's history. Imaging is only indicated in patients 
with a positive neurological exam or presence of a "red flag" $[54,56]$.

\section{Evidence base for manual treatment Systematic reviews (most recent)}

The recently published best evidence synthesis by the Bone and Joint Decade 2000-2010 Task Force on Neck Pain and Its Associated Disorders represents the most recent and comprehensive systematic review of the literature for noninvasive interventions, including manual treatment, for neck pain [55]. For whiplash associated disorders, they concluded that mobilization and exercises appear more beneficial than usual care or physical modalities. For Grades I and II neck pain, they concluded that the evidence suggests that manual treatment (including manipulation and mobilization) and exercise interventions, low-level laser therapy and perhaps acupuncture are more effective than no treatment, sham or alternative interventions. No one type of treatment was found to be clearly superior to any other. They also note that manipulation and mobilization yield comparable results. Conclusions regarding massage could not be made due to lack of evidence.

Since 2003, there were five other systematic reviews [29,57-60]. One found that spinal manipulation was effective for non-specific neck pain alone and in combination with exercise [29], while two found effectiveness only for the combination of spinal manipulation and exercise $[58,60]$. Differences between review conclusions are expected. It is likely they can be attributed to additional primary studies and diversity in review strategies, including inclusion criteria, methodological quality scoring, and evidence determination.

\section{Evidence-based clinical guidelines}

The American Physical Therapy Association's guidelines on neck pain recommends utilizing cervical manipulation and mobilization procedures to reduce neck pain based on strong evidence [56]. They found cervical manipulation and mobilization with exercise to be more effective for reducing neck pain and disability than manipulation and mobilization alone. Thoracic spine manipulation is also recommended for reducing pain and disability in patients with neck and neck-related arm pain based on weak evidence.

\section{Recent randomized clinical trials not included in above}

Häkkinen et al used a cross-over design to compare manual therapy and stretching for chronic neck pain [61]. Manual therapy was more effective than stretching at four weeks, but no difference between the two therapies was noted at 12 weeks. This study had a high risk of bias.

González-Iglesias et al examined the effectiveness of adding general thoracic spine manipulation to electrotherapy/thermal therapy for acute neck pain. In two separate trials they found an advantage for the manipulation group in terms of pain and disability $[62,63]$. The trials had moderate to low risk of bias.
Walker et al compared manual therapy with exercise to advice to stay active and placebo ultrasound [64]. The manual therapy group reported less pain (in the short term) and more improvement and less disability (in the long term) than the placebo group. This study had a low risk of bias.

Cleland et al [65] showed that thoracic spine thrust mobilization/manipulation results in a significantly greater short-term reduction in pain and disability than does thoracic non-thrust mobilization/manipulation in people with mostly subacute neck pain. The study had a low risk of bias.

Fernandez et al [66] found that adding thoracic manipulation to a physical therapy program was effective in treating neck pain due to whiplash injury. The study had a high risk of bias.

Savolainen et al [49] compared the effectiveness of thoracic manipulations with instructions for physiotherapeutic exercises for the treatment of neck pain in occupational health care. The effect of the manipulations was more favorable than the personal exercise program in treating the more intense phase of pain. The study had a moderate risk of bias.

Zaproudina et al [67] assessed the effectiveness of traditional bone setting (mobilization) of joints of extremities and the spine for chronic neck pain compared with conventional physiotherapy or massage. The traditional bone setting was superior to the other two treatments in both in the short and long term. The study had a moderate risk of bias.

Sherman et al compared massage therapy to self-care for chronic neck pain. Massage was superior to self-care at 4 weeks for both neck disability and pain [68]. A greater proportion of massage patients reported a clinically significant improvement in disability than self-care patients at four weeks, and more massage patients reported a clinically significant improvement in pain at four and 10 weeks. No statistically significant differences between groups were noted at 26 weeks. This study had a low risk of bias.

Evidence Summary (See Figure 3)

- Moderate quality evidence that mobilization combined with exercise is effective for acute whiplashassociated disorders [55].

- Moderate quality evidence that spinal manipulation/mobilization combined with exercise is effective for chronic non-specific neck pain [55,58].

- Moderate quality evidence that thoracic spinal manipulation/mobilization is effective for acute/ subacute non-specific neck pain $[62,63,65,66]$.

- Moderate quality evidence that spinal manipulation is similar to mobilization for chronic non-specific neck pain [55,58].

- Moderate quality evidence that massage therapy is effective for non-specific chronic neck pain [68]. 
- Inconclusive evidence in a favorable direction for cervical spinal manipulation/mobilization alone for neck pain of any duration $[29,55,58]$.

Other effective non-invasive physical treatments or patient education

Exercise, low-level laser therapy, acupuncture [55]

\section{Coccydynia}

Definition

Coccydynia is defined as symptoms of pain in the region of the coccyx [69].

\section{Diagnosis}

Diagnosis of coccydynia is derived from the patient's history and exam with no indicators of potentially serious pathology. Imaging is only indicated in patients with a presence of a "red flag" [46,69].

\section{Evidence base for manual treatment} Systematic reviews (most recent)

None located

\section{Evidence-based clinical guidelines}

None located

Recent randomized clinical trials not included in above

Maigne et al [70] found manipulation was more effective than placebo for pain relief and disability in the treatment of coccydynia at one month. This study had a moderate risk of bias.

Evidence Summary (See Figure 3)

- Inconclusive evidence in a favorable direction for the use of spinal manipulation in the treatment of coccydynia [70].

Other effective non-invasive physical treatments or patient education

None

\section{Shoulder pain \\ Definition}

Shoulder pain is defined as soreness, tension, and/or stiffness in the anatomical region of the shoulder and can be secondary to multiple conditions including, but not limited to rotator cuff disease and adhesive capsulitis.

Diagnosis

Diagnosis of shoulder pain is derived mainly from the patient's history and physical exam with no indicators of potentially serious pathology. Imaging studies are confirmatory for diagnoses of rotator cuff disorders, osteoarthritis, glenohumeral instability, and other pathologic causes of shoulder pain [71].

\section{Evidence base for manual treatment} Systematic reviews (most recent)

Two systematic reviews evaluated the benefit of manual therapy for shoulder pain [72,73]. Six RCTs evaluating the effectiveness of manual therapy for the treatment of shoulder pain were included [74-79]. Five of the trials evaluated mobilization [74-77,79] while one trial evaluated the use of manipulation and mobilization [78] for shoulder pain. The review concluded there is weak evidence that mobilization added benefit to exercise for rotator cuff disease.

\section{Evidence-based clinical guidelines}

The Philadelphia Panel's evidence based clinical practice guidelines on selected rehabilitation interventions for shoulder pain concluded there is insufficient evidence regarding the use of therapeutic massage for shoulder pain [80].

\section{Recent randomized clinical trials not included in above}

Vermeulen et al [81] found that high-grade mobilization techniques were more effective than low-grade mobilization techniques for active range of motion (ROM), passive ROM, and shoulder disability for adhesive capsulitis at three to 12 months. No differences were noted for pain or mental and physical general health. Both groups showed improvement in all outcome measures. This study had low risk of bias.

van den Dolder and Roberts [82] found massage was more effective than no treatment for pain, function, and ROM over a two week period in patients with shoulder pain. This study had moderate risk of bias.

Bergman et al [51] found no differences between groups during the treatment period ( $6 \mathrm{wks})$. More patients reported being "recovered" in the usual care plus manipulative/mobilization group at 12 and 52 weeks compared to usual care alone. This study had low risk of bias.

Johnson et al [83] found no differences in pain or disability between anterior and posterior mobilization for the care of adhesive capsulitis. This study had a high risk of bias.

Guler-Uysal et al [84] concluded that deep friction massage and mobilization exercises was superior in the short term to physical therapy including diathermy for adhesive capsulitis. The study had a high risk of bias.

\section{Evidence Summary (See Figure 4)}

- Moderate quality evidence that high-grade mobilization is superior to low-grade mobilization for reduction of disability, but not for pain, in adhesive capsulitis [81].

- Inconclusive evidence in an unclear direction for a comparison of anterior and posterior mobilization for adhesive capsulitis [83].

- Moderate evidence favors the addition of manipulative/mobilization to medical care for shoulder girdle pain and dysfunction [51].

- Inconclusive evidence in a favorable direction for massage in the treatment of shoulder pain [82].

- Inconclusive evidence in a favorable direction for mobilization/manipulation in the treatment of rotator cuff pain [72]. 
Other effective non-invasive physical treatments or patient education

Exercise therapy [80]

\section{Lateral epicondylitis \\ Definition}

Lateral epicondylitis is defined as pain in the region of the lateral epicondyle which is exacerbated by active and resistive movements of the extensor muscles of the forearm [85].

Diagnosis

Diagnosis is made solely from the patient's history and clinical examination [71].

\section{Evidence base for manual treatment Systematic reviews (most recent)}

Three systematic reviews evaluating the benefit of manual therapy for lateral epicondylitis have been identified [86-88]. Eight RCTs were included [89-96] in the systematic reviews examining the effect of various manual therapies including elbow [89] and wrist manipulation [92], cervical spine [90] and elbow mobilization [91,93,95], and cross-friction massage [94-96]. Bisset et al [86] concluded there is some evidence of positive initial effects of manual techniques (massage/mobilization) for lateral epicondylitis, but no long term evidence. Smidt et al [88] concluded there is insufficient evidence to draw conclusions on the effectiveness of mobilization techniques for lateral epicondylitis.

\section{Evidence-based clinical guidelines}

None located

Recent randomized clinical trials not included in above

Verhaar et al [97] showed that corticosteroid injection was superior to Cyriax physiotherapy for the number of pain free subjects at six weeks. No differences between groups were noted at one year. This study had a high risk of bias.

Bisset et al [98] found corticosteroid injections were superior to elbow mobilization with exercise which was superior to wait and see approaches for pain-free grip strength, pain intensity, function, and global improvement at six weeks. However, both elbow mobilization with exercise and the wait and see approach were superior to corticosteroid injections at six months and one year for all of the previously reported outcomes. This study had a low risk of bias.

Nourbakhsh and Fearon [99] found oscillating energy manual therapy (tender point massage) was superior to placebo manual therapy for pain intensity and function. This study had a high risk of bias due to sample size (low risk of bias otherwise).

\section{Evidence Summary (See Figure 4)}

- Moderate quality evidence that elbow mobilization with exercise is inferior to corticosteroid injections in the short term and superior in the long term for lateral epicondylitis [98].

- Inconclusive evidence in a favorable direction regarding the use of manual oscillating tender point therapy of the elbow for lateral epicondylitis [99].

Other effective non-invasive physical treatments or patient education

Laser therapy, acupuncture $[86,100,101]$

\section{Carpal tunnel syndrome \\ Definition}

Carpal tunnel syndrome is defined as compression of the median nerve as it passes through the carpal tunnel in the wrist [102].

\section{Diagnosis}

Diagnosis of carpal tunnel syndrome is made from the patient's history, physical exam, and confirmatory electrodiagnostic tests [102].

\section{Evidence base for manual treatment \\ Systematic reviews (most recent)}

Since 2003, four systematic reviews evaluated the benefit of manual therapy for carpal tunnel syndrome [87,103-105]. Two RCTs evaluating the effectiveness of manual therapy were included $[106,107]$. One of the trials examined the use of spinal and upper extremity manipulation [106], while the other trial examined the use of wrist manipulation [107] for carpal tunnel syndrome. The reviews concluded uncertain or limited evidence for manipulation/mobilization.

\section{Evidence-based clinical guidelines}

The American Academy of Orthopaedic Surgeons clinical practice guideline on the treatment of carpal tunnel syndrome [102] made no recommendations for or against the use of manipulation or massage therapy due to insufficient evidence.

\section{Recent randomized clinical trials not included in above} None

\section{Evidence Summary (See Figure 4)}

- Inconclusive evidence in a favorable direction for manipulation/mobilization in the treatment of carpal tunnel syndrome $[87,103,105]$.

Other effective non-invasive physical treatments or patient education

Splinting [102]

Hip pain

\section{Definition}

Hip pain is defined as soreness, tension, and/or stiffness in the anatomical region of the hip and can be secondary to multiple conditions including hip osteoarthritis.

\section{Diagnosis}

Diagnosis of hip pain is derived from the patient's history and physical exam with an unremarkable neurological 
exam and no indicators of potentially serious pathology. Imaging studies are confirmatory for diagnoses of moderate or severe osteoarthritis $[108,109]$.

\section{Evidence base for manual treatment Systematic reviews (most recent)}

One systematic review evaluating manual therapy for hip pain has been published [110]. One RCT evaluating the effectiveness of hip manipulation for the treatment of hip osteoarthritis was included in the published systematic review [111]. The review concluded there is limited evidence for manipulative therapy combined with multimodal or exercise therapy for hip osteoarthritis.

\section{Evidence-based clinical guidelines}

The NICE national clinical guidelines for care and management of adults with osteoarthritis [112] recommends manipulation and stretching should be considered as an adjunct to core treatment, particularly for osteoarthritis of the hip. This recommendation is based on the results of one RCT.

The orthopaedic section of the American Physical Therapy Association's guidelines on hip pain and mobility deficits [108] recommends clinicians should consider the use of manual therapy procedures to provide shortterm pain relief and improve hip mobility and function in patients with mild hip osteoarthritis based on moderate evidence.

\section{Recent randomized clinical trials not included in above}

Licciardone et al found decreased rehabilitation efficiency with osteopathic manipulative therapy (OMT) compared to sham OMT following hip arthroplasty. No other significant differences were found between the two groups [113]. This study had a high risk of bias.

\section{Evidence Summary (See Figure 4)}

- Moderate quality evidence that hip manipulation is superior to exercise for the treatment of the symptoms of hip osteoarthritis [111].

- Inconclusive evidence in a non-favorable direction regarding osteopathic manipulative therapy for rehabilitation following total hip arthroplasty [113].

Other effective non-invasive physical treatments or patient education

Exercise therapy, advice about weight loss, and appropriate footwear $[108,112,114]$

\section{Knee pain \\ Definition}

Knee pain is defined as soreness, tension, and/or stiffness in the anatomical region of the knee and can be secondary to multiple conditions including knee osteoarthritis or patellofemoral pain syndrome.

\section{Diagnosis}

Diagnosis of knee pain is derived from the patient's history and physical exam with an unremarkable neurological exam and no indicators of potentially serious pathology. Imaging studies are confirmatory for diagnoses of moderate or severe osteoarthritis $[109,112]$.

\section{Evidence base for manual treatment Systematic reviews (most recent)}

As of September 2009, one systematic review evaluating the benefit of manual therapy for knee pain has been identified [110]. Ten RCT's evaluating the effectiveness of manual therapy for the treatment of knee pain were included in the published systematic review [115-124]. Both osteoarthritis knee pain and patellofemoral pain syndrome were included in the conditions reviewed. Various manual therapy techniques including spinal mobilization [115,116,119], spinal manipulation [118,123], knee mobilization [115-117,120-124], and knee manipulation [121] were examined within the review. The review concludes there is fair evidence for manipulative therapy of the knee and/or full kinetic chain (Sacro-iliac to foot), combined with multimodal or exercise therapy for knee osteoarthritis and patellofemoral pain syndrome.

\section{Evidence-based clinical guidelines}

The NICE national clinical guidelines for care and management of adults with osteoarthritis [112] recommends manipulation and stretching should be considered as an adjunct to core treatment.

\section{Recent randomized clinical trials not included in above}

Pollard et al [125] assessed a manual therapy protocol compared to non-forceful manual contact (control). They concluded that a short term of manual therapy significantly reduced pain compared to the control group. This study had a high risk of bias.

Perlman et al [126] found massage therapy was more effective than wait list control for osteoarthritis related knee pain, stiffness, and function. This study had a high risk of bias.

Licciardone et al [113] assessed osteopathic manipulative treatment following knee arthroplasty. This study found decreased rehabilitation efficiency with OMT compared to sham OMT; otherwise, no significant differences were found between the two groups. This study had a high risk of bias.

Evidence Summary (See Figure 4)

- Moderate quality evidence that manual therapy of the knee and/or full kinetic chain (SI to foot) combined with multimodal or exercise therapy is effective for the symptoms of knee osteoarthritis [110].

- Moderate quality evidence that manual therapy of the knee and/or full kinetic chain (SI to foot) combined with multimodal or exercise therapy is effective for patellofemoral pain syndrome [110].

- Inconclusive evidence in a favorable direction that massage therapy is effective for the symptoms of knee osteoarthritis [126]. 
- Inconclusive evidence in a non-favorable direction for the effectiveness of osteopathic manipulative therapy for rehabilitation following total hip or knee arthroplasty [113].

Other effective non-invasive physical treatments or patient education

Exercise therapy, advice about weight loss, appropriate footwear, pulsed electromagnetic field therapy, acupuncture, and TENS [112,127-131]

\section{Ankle and foot conditions}

\section{Definition}

A variety of conditions are included under ankle and foot conditions including ankle sprains, plantar fasciitis, morton's neuroma, hallux limitus/rigidus, and hallux abducto valgus.

\section{Diagnosis}

The diagnosis of ankle/foot conditions relies mainly on the patient's history and physical examination. Imaging studies are indicated for morton's neuroma or in the presence of potential pathology [109].

\section{Evidence base for manual treatment Systematic reviews (most recent)}

As of September 2009, two systematic reviews evaluating the benefit of manual therapy for ankle and foot conditions have been published [110,132]. The ankle and foot conditions reviewed included ankle sprain, plantar fasciitis, morton's neuroma, hallux limitus, and hallux abducto valgus. Thirteen RCTs evaluating the effectiveness of manual therapy for the treatment of various ankle and foot conditions were included in the published systematic reviews [133-145]. Of the thirteen trials, six examined the use of ankle/foot manipulation $[134,136,137,139-141]$, six examined the use of ankle/ foot mobilization [133,135,138,143-145], and one trial examined the combined use of manipulation and mobilization [142].

The review by Brantingham et al concluded there is fair evidence for manipulative therapy of the ankle and/ or foot combined with multimodal or exercise therapy for ankle inversion sprain [110]. The same authors found limited evidence for manipulative therapy combined with multimodal or exercise therapy for plantar fasciitis, metatarsalgia, and hallux limitus and insufficient evidence for the use of manual therapy for hallux abducto valgus.

The review by van der Wees et al concluded it is likely that manual mobilization has an initial effect on dorsiflexion range of motion after ankle sprains [132].

\section{Evidence-based clinical guidelines}

None making recommendations based on RCTs were located

\section{Recent randomized clinical trials not included in above}

Wynne et al found an osteopathic manipulative therapy group had greater improvement in plantar fasciitis symptoms versus placebo control. This study had a high risk of bias [146].

Cleland et al compared manual therapy with exercise to electrotherapy with exercise for patients with plantar heel pain [147]. They found manual therapy plus exercise was superior. This study had a low risk of bias.

Lin et al found the addition of manual therapy (mobilization) to a standard physiotherapy program provided no additional benefit compared to the standard physiotherapy program alone for rehabilitation following ankle fracture [148]. This study had a low risk of bias.

\section{Evidence Summary (See Figure 4)}

- Moderate quality evidence that mobilization is of no additional benefit to exercise in the rehabilitation following ankle fractures [148].

- Moderate quality evidence that manual therapy of the foot and/or full kinetic chain (SI to foot) combined with exercise therapy is effective for plantar fasciitis [147].

- Inconclusive evidence in a favorable direction for the effectiveness of manual therapy with multimodal or exercise therapy for ankle sprains [110].

- Inconclusive evidence in a favorable direction regarding the effectiveness of manual therapy for morton's neuroma, hallux limitus, and hallux abducto valgus [110].

Other effective non-invasive physical treatments or patient education

Stretching and foot orthoses for plantar fasciitis [149], ankle supports for ankle sprains [150]

\section{Temporomandibular disorders \\ Definition}

Temporomandibular disorders consist of a group of pathologies affecting the masticatory muscles, temporomandibular joint, and related structures [151].

\section{Diagnosis}

Diagnosis of temporomandibular disorders is derived from the patient's history and physical exam with no indicators of potentially serious pathology [151,152].

\section{Evidence base for manual treatment Systematic reviews (most recent)}

As of September 2009, two systematic reviews evaluating the benefit of manual therapy for temporomandibular dysfunction have been published [153,154]. Three RCTs evaluating the effectiveness of manual therapy were included in the published systematic reviews [155-157]. Two of the trials examined the effectiveness of mobilization $[155,156]$ and one trial assessed massage 
[157]. The reviews conclude there is limited evidence for the use of manual therapy in the treatment of temporomandibular dysfunction.

\section{Evidence-based clinical guidelines}

None located

Recent randomized clinical trials not included in above

Monaco et al [158] examined the effects of osteopathic manipulative treatment on mandibular kinetics compared to a no treatment control group; however, no between group analysis was performed. This study had a high risk of bias.

Ismail et al [159] found physical therapy including mobilization in addition to splint therapy was superior to splint therapy alone after three months of treatment for active mouth opening. No differences were found between groups for pain. This study had a moderate risk of bias.

\section{Evidence Summary (See Figure 5)}

- Inconclusive evidence in a favorable direction regarding mobilization and massage for temporomandibular dysfunction [154].

\section{Other effective non-invasive physical treatments or patient} education

None

\section{Fibromyalgia}

Definition

Fibromyalgia syndrome (FMS) is a common rheumatological condition characterized by chronic widespread pain and reduced pain threshold, with hyperalgesia and allodynia [160].

Diagnosis

Diagnosis of fibromyalgia is made primarily from the patient's history and physical exam. The American College of Rheumatology have produced classification criteria for fibromyalgia including widespread pain involving both sides of the body, above and below the waist for at least three months and the presence of 11 out of 18 possible pre-specified tender points [161].

\section{Evidence base for manual treatment}

\section{Systematic reviews (most recent)}

Since 2004, three systematic reviews evaluating the benefit of manual therapy for fibromyalgia have been published [162-164]. Six RCTs evaluating the effectiveness of manual therapy for the treatment of fibromyalgia were included in the published systematic reviews [165-170]. Five of the studies assessed the effectiveness of spinal manipulation for fibromyalgia [165-169], while one assessed the effectiveness of massage [170].

Schneider et al [162] conclude there is moderate level evidence from several RCTs and a systematic review [171] that massage is helpful in improving sleep and reducing anxiety in chronic pain; however, few of the studies included in the systematic review [162] specifically investigated fibromyalgia.

Ernst [163] states that the current trial evidence is insufficient to conclude that chiropractic is an effective treatment of fibromyalgia.

Goldenberg et al [164] conclude there is weak evidence of efficacy for chiropractic, manual, and massage therapy in the treatment of fibromyalgia.

\section{Evidence-based clinical guidelines}

The 2007 a multidisciplinary task force with members from 11 European countries published evidence based recommendation for FMS [160]. The task force notes the clinical trial evidence for manual therapy is lacking. Randomized clinical trials not included in above Ekici et al [172] found improvement was higher in the manual lymph drainage group compared to connective tissue massage on the fibromyalgia impact questionnaire, but no differences were noted between groups for pain, pain pressure threshold, or health related quality of life. This study had a moderate risk of bias.

\section{Evidence Summary (See Figure 5)}

- Inconclusive evidence in a favorable direction regarding the effectiveness of massage and manual lymph drainage for the treatment of fibromyalgia [162,172].

- Inconclusive evidence in an unclear direction regarding the effectiveness of spinal manipulation for the treatment of fibromyalgia [162].

\section{Other effective non-invasive physical treatments or patient} education

Heated pool treatment with or without exercise, supervised aerobic exercise [160,173]

\section{Myofascial Pain Syndrome \\ Definition}

Myofascial pain syndrome is a poorly defined condition that requires the presence of myofascial trigger points.

\section{Diagnosis}

Diagnosis of myofascial pain syndrome is made exclusively from the patient's history and physical exam.

\section{Evidence base for manual treatment} Systematic reviews (most recent)

As of September 2009, one systematic review evaluating the benefit of manual therapy for myofascial pain syndrome was identified, which concludes there is limited evidence to support the use of some manual therapies for providing long-term relief of pain at myofascial trigger points [174]. Fifteen RCTs evaluating the effectiveness of manual therapy for the treatment of myofascial pain syndrome were included in the published systematic review [90,175-188]. Only two of the truly randomized trials assessed the effectiveness of manual therapy beyond the immediate post-treatment period [175,178]. 
One trial assessed the effectiveness of massage combined with other therapies, while the other trial assessed the effectiveness of self-treatment with ischemic compression.

\section{Evidence-based clinical guidelines}

None

\section{Recent randomized clinical trials not included in above}

None

\section{Evidence Summary (See Figure 5)}

- Inconclusive evidence in a favorable direction regarding the effectiveness of massage for the treatment of myofascial pain syndrome [174].

Other effective non-invasive physical treatments or patient education

Laser, acupuncture [174]

\section{Migraine Headache \\ Definition}

Migraine headache is defined as recurrent/episodic moderate or severe headaches which are usually unilateral, pulsating, aggravated by routine physical activity, and are associated with either nausea, vomiting, photophobia, or phonophobia $[189,190]$.

\section{Diagnosis}

Diagnosis of migraine headaches is made primarily from the patient's history and a negative neurological exam. Neuroimaging is only indicated in patients with a positive neurological exam or presence of a "red flag" [190].

\section{Evidence base for manual treatment Systematic reviews (most recent)}

Since 2004, two systematic reviews evaluated the benefit of manual therapy for migraine headache [191,192]. The reviews evaluated three RCTs on spinal manipulation [193-195]. Astin and Ernst [191] concluded that due to methodological limitations of the RCTs, it is unclear whether or not spinal manipulation is an effective treatment for headache disorders. In contrast, the conclusion from a Cochrane review [192] was that spinal manipulation is an effective option for the care of migraine headache. The conclusions of the two reviews differed in methodology for determining RCT quality and the strength of evidence. Astin and Ernst [191] evaluated study quality using a scale that is no longer recommended by the Cochrane Collaboration and did not apply evidence rules for their conclusions. The Cochrane review [192] used a pre-specified, detailed protocol for synthesizing the evidence from the quality, quantity, and results of RCTs.

\section{Evidence-based clinical guidelines}

The SIGN guidelines [190] for the diagnosis and management of headache in adults concludes the evidence of effectiveness for manual therapy is too limited to lead to a recommendation.

\section{Recent randomized clinical trials not included in above}

Lawler and Cameron [196] found that massage therapy significantly reduced migraine frequency in the short term compared to filling out a diary with no other treatment. This study had a high risk of bias.

\section{Evidence Summary (See Figure 5)}

- Moderate quality evidence that spinal manipulation has an effectiveness similar to a first-line prophylactic prescription medication (amitriptyline) for the prophylactic treatment of migraine [195].

- Inconclusive evidence in a favorable direction comparing spinal manipulation to sham interferential [194].

- Inconclusive evidence in a favorable direction regarding the use of massage therapy alone [196].

Other effective non-invasive physical treatments or patient education

Trigger avoidance, stress management, acupuncture, biofeedback $[190,197,198]$

\section{Tension- Type Headache \\ Definition}

Tension-type headache is defined as a headache that is pressing/tightening in quality, mild/moderate in intensity, bilateral in location, and does not worsen with routine physical activity $[189,190]$.

\section{Diagnosis}

Diagnosis of tension-type headaches is made primarily from the patient's history and a negative neurological exam [190]. Neuroimaging is only indicated in patients with a positive neurological exam or presence of a "red flag" [190].

\section{Evidence base for manual treatment \\ Systematic reviews (most recent)}

Since 2002, five systematic reviews evaluated the benefit of manual therapy for tension-type headache [191,192,199-201]. Eleven RCTs were included in the published systematic reviews [202-212]. Three of the RCTs assessed the effectiveness of spinal manipulation $[202,206,210]$, six of the trials evaluated the use of combined therapies including a form of manual therapy [203,207-209,211,212], one trial evaluated a craniosacral technique [204], and the remaining trial compared connective tissue manipulation to mobilization [205]. The reviews generally conclude there is insufficient evidence to draw inference on the effectiveness of manual therapy in the treatment of tension-type headache. An exception is the Cochrane review [192] which found that some inference regarding spinal manipulation could be made from two trials with low risk of bias. One trial [202] showed that for the prophylactic treatment of chronic tension-type headache, amitriptyline (an effective drug) is more effective than spinal manipulation during 
treatment. However, spinal manipulation is superior in the short term after cessation of both treatments, but this could be due to a rebound effect of the medication withdrawal. The other trial [203] showed that spinal manipulation in addition to massage is no more effective than massage alone for the treatment of episodic tension-type headache.

\section{Evidence-based clinical guidelines}

The SIGN guideline [190] for the diagnosis and management of headache in adults draws no conclusions.

Recent randomized clinical trials not included in above Anderson and Seniscal [213] found that participants receiving osteopathic manipulation in addition to relaxation therapy had significant improvement in headache frequency compared to relaxation therapy alone. This study had a moderate risk of bias.

Evidence Summary (See Figure 5)

- Moderate quality evidence that spinal manipulation in addition to massage is no more effective than massage alone for the treatment of episodic tension-type headache $[192,203]$.

- Inconclusive evidence in an unclear direction regarding the use of spinal manipulation alone or in combination with therapies other than massage for most forms of tension-type headache [191,192,199-202].

Other effective non-invasive physical treatments or patient education

Acupuncture, biofeedback [198,214]

\section{Cervicogenic Headache \\ Definition}

Cervicogenic headache is defined as unilateral or bilateral pain localized to the neck and occipital region which may project to regions on the head and/or face. Head pain is precipitated by neck movement, sustained awkward head positioning, or external pressure over the upper cervical or occipital region on the symptomatic side $[189,190,215]$.

\section{Diagnosis}

Diagnosis of cervicogenic headaches is made primarily from the patient's history and a negative neurological exam. Neuroimaging is only indicated in patients with a positive neurological exam or presence of a "red flag" [190].

\section{Evidence base for manual treatment Systematic reviews (most recent)}

Since 2002, four systematic reviews have been published on manual therapy for cervicogenic headache $[55,191,192,216]$. The reviews made inference based on six RCTs that evaluated a range of manual therapy treatments including spinal manipulation [217-222], mobilization $[217,220]$, and friction massage $[220,222]$. Astin and Ernst [191] concluded that due to methodological limitations of the RCTs, it is unclear whether or not spinal manipulation is an effective treatment for headache disorders. In contrast, a Cochrane review [192]concluded that spinal manipulation is an effective option for the care of cervicogenic headache. The conclusions of the two reviews differed in methodology for determining RCT quality and the strength of evidence. Ernst [191] evaluated study quality using a scale that is no longer recommended by the Cochrane Collaboration and did not apply evidence rules for their conclusions. The Cochrane review [192] used a pre-specified, detailed protocol for synthesizing the evidence from the quality, quantity, and results of RCTs.

\section{Evidence-based clinical guidelines}

The SIGN guidelines [190] for the diagnosis and management of headache in adults concluded spinal manipulation should be considered in patients with cervicogenic headache.

Recent randomized clinical trials not included in above

Hall et al [223] evaluated the efficacy of apophyseal glide of the upper cervical region in comparison to a sham control. They found a large clinically important and statistically significant advantage of the intervention over sham for pain intensity. The study had a low risk of bias.

Evidence Summary (See Figure 5)

- Moderate quality evidence that spinal manipulation is more effective than placebo manipulation, friction massage, and no treatment [192].

- Moderate quality evidence that spinal manipulation is similar in effectiveness to exercise [220].

- Moderate quality evidence that self-mobilizing natural apophyseal glides are more effective than placebo [223].

- Inclusive evidence that deep friction massage with trigger point therapy is inferior to spinal manipulation [221].

- Inconclusive evidence in an unclear direction for the use of mobilization [192].

Other effective non-invasive physical treatments or patient education

Neck exercises [192]

\section{Miscellaneous Headache \\ Definition}

Headaches not classified as tension-type, migraine, or cervicogenic in nature according to the International Headache Society's 2004 diagnostic criteria [189].

\section{Evidence base for manual treatment}

\section{Systematic reviews (most recent)}

One systematic review (2004) evaluated the benefit of manual therapy for other types of chronic headache [192]. One RCT evaluating the use of mobilization for 
post-traumatic (post-concussive) headache was included [224]. The review found the evidence to be inconclusive. Evidence-based clinical guidelines

None

Recent randomized clinical trials not included in above

None

Evidence Summary (See Figure 5)

- Inconclusive evidence in a favorable direction regarding mobilization for post-traumatic headache [224].

Other effective non-invasive physical treatments or patient education

None

\section{Asthma}

Definition

Asthma is a common, complex chronic disorder of the airways that is characterized by variable and recurring symptoms, airflow obstruction, bronchial hyperresponsiveness, and an underlying inflammation [225].

\section{Diagnosis}

The diagnosis is made through the combination of the patient's history, upper respiratory physical exam, and pulmonary function testing (spirometry). Patient administered peak flow measurement is often used to monitor effects of treatment $[225,226]$.

\section{Evidence base for manual treatment} Systematic reviews

Since 2002, four systematic reviews, one a Cochrane review, on manual therapy for asthma have been published [227-230]. Of the total of five RCTs on the effectiveness of manual therapy [231-235] available from the searched literature, two investigated chiropractic spinal manipulation for chronic asthma, one in adults [231] and the other in children [232]. Two trials assessed the effectiveness on chronic asthma in children, one examined osteopathic manipulative/manual therapy [233], and the other massage [234]. The fifth trial evaluated the effect of foot manual reflexology for change in asthma symptoms and lung function in adults [235]. The four systematic reviews collectively concluded that the evidence indicates that none of the manual therapy approaches have been shown to be superior to a suitable sham manual control on reducing severity and improving lung function but that clinically important improvements occur over time during both active and sham treatment.

\section{Evidence-based clinical guidelines}

The asthma guidelines by The US National Heart, Lung, and Blood Institutes [225] and by The British Thoracic Society [226] both conclude that there is insufficient evidence to recommend the use of chiropractic or related manual techniques in the treatment of asthma.

\section{Recent randomized clinical trials not included in above}

None

Evidence Summary (See Figures 6 \&7)

- There is moderate quality evidence that spinal manipulation is not effective (similar to sham manipulation) for the treatment of asthma in children and adults on lung function and symptom severity $[227,228]$.

- There is inconclusive evidence in a non-favorable direction regarding the effectiveness of foot manual reflexology for change in asthma symptoms and lung function in adults [235].

- There is inconclusive evidence in a favorable direction regarding the effectiveness of osteopathic manipulative treatment for change in asthma symptoms and lung function in children [233].

- There is inconclusive evidence in an unclear direction regarding the effectiveness of massage for change in asthma symptoms and lung function in children [234].

\section{Other effective non-invasive physical treatments or patient} education

Education and advice on self-management, maintaining normal activity levels, control of environmental factors and smoking cessation [225,226]

\section{Pneumonia}

Definition

Pneumonia is defined as an acute inflammation of the lungs caused by infection [236,237].

Diagnosis

Diagnosis of pneumonia relies primarily on chest radiography in conjunction with the patient's history, examination, and laboratory findings [236,237].

\section{Evidence base for manual treatment}

\section{Systematic reviews (most recent)}

Since 2007, one systematic review evaluating the benefit of manual therapy for pneumonia has been published [230]. One RCT evaluating the effectiveness of manual therapy for the treatment of pneumonia was included in the published systematic review [238]. The included trial assessed the effectiveness of osteopathic spinal manipulation for acute pneumonia in hospitalized elderly adults. The review concluded there is promising evidence for the potential benefit of manual procedures for hospitalized elderly patients with pneumonia. Our risk of bias assessment places this trial in the moderate risk of bias category.

\section{Evidence-based clinical guidelines}

None addressing the use of manual therapy

Randomized clinical trials not included in above

None 


\section{Evidence Summary (See Figure 6)}

- There is inconclusive evidence in a favorable direction regarding the effectiveness of osteopathic manual treatment for the treatment of acute pneumonia in elderly hospitalized patients [238].

Other effective non-invasive physical treatments or patient education

Cases of pneumonia that are of public health concern should be reported immediately to the local health department. Respiratory hygiene measures, including the use of hand hygiene and masks or tissues for patients with cough, should be used in outpatient settings as a means to reduce the spread of respiratory infections [236,237].

\section{Vertigo}

\section{Definition}

Vertigo is defined as a false sensation of movement of the self or the environment. Vertigo is a sensation and not necessarily a diagnosis as there are multiple underlying pathologies responsible for vertigo [239,240].

\section{Diagnosis}

Diagnosis of vertigo relies primarily on the patient's history and clinical examination. Potential causes of vertigo include both pathological disorders such as vertebrobasilar insufficiency or central nervous system lesions as well as more benign causes such as cervicogenic vertigo or benign paroxysmal positional vertigo [239].

\section{Evidence base for manual treatment Systematic reviews (most recent)}

Since 2004, two systematic reviews evaluating the benefit of manual therapy for vertigo have been published $[230,240]$. One RCT evaluating the effectiveness of mobilization and soft-tissue massage for the treatment of cervicogenic vertigo was included in both published systematic reviews [241]. One review concluded limited evidence of effectiveness [240]. The other concluded effectiveness, but the inference was on the inclusion of other types of evidence [230].

\section{Evidence-based clinical guidelines}

None addressing the use of manual therapy

Recent randomized clinical trials not included in above Reid et al [242] compared sustained natural apophyseal glides (SNAGs), delivered manually by a therapist, to detuned laser treatment for the treatment of cervicogenic dizziness. Patients receiving SNAGs reported less dizziness, disability and cervical pain after six weeks, but not at 12 weeks. This study had a low risk of bias.

\section{Evidence Summary (See Figure 5)}

- Moderate quality evidence that manual treatment (specifically sustained natural apophyseal glides) is an effective treatment for cervicogenic dizziness, at least in the short term [242].

\section{Other effective non-invasive physical treatments or patient} education

Particle repositioning maneuvers for benign paroxysmal positional vertigo, vestibular rehabilitation $[239,243]$

\section{Infantile Colic \\ Definition}

Colic is a poorly defined condition characterized by excessive, uncontrollable crying in infants.

\section{Diagnosis}

The diagnosis of colic is based solely on the patient's history and the absence of other explanations for the excessive crying. The "rule of threes" is the most common criteria used in making a diagnosis of colic. The rule of three's is defined as an otherwise healthy and well fed infant with paroxysms of crying and fussing lasting for a total of three hours a day and occurring more than three days a week for at least three weeks $[244,245]$.

\section{Evidence base for manual treatment \\ Systematic reviews (most recent)}

Since 2003, six systematic reviews evaluating the benefit of manual therapy for infantile colic have been published [230,245-249]. Two of the systematic reviews evaluated the effectiveness of manual therapy for non-musculoskeletal [247] and pediatric [248] conditions as a whole but fail to draw specific conclusions regarding the use of manual therapy for infantile colic. Of the eight RCTs evaluating the effectiveness of manual therapy for the treatment of colic, five were included in the published systematic reviews [250-254]. All five of the trials assessed the effectiveness of chiropractic spinal manipulation for infantile colic. All four systematic reviews concluded there is no evidence manual therapy is more effective than sham therapy for the treatment of colic.

\section{Evidence-based clinical guidelines}

No clinical guidelines located

\section{Randomized clinical trials not included in above}

Hayden et al [255] found cranial osteopathy was more effective than no treatment for crying duration. This study had a high risk of bias

Huhtala et al [256] found no difference between groups treated with massage therapy or given a crib vibrator for crying duration. This study had a high risk of bias.

Arikan et al [257] found all four interventions (massage, sucrose solution, herbal tea, hydrolysed formula) showed improvement compared to a no treatment control group. This study had a moderate risk of bias.

\section{Evidence Summary (See Figure 7)}

- Moderate quality evidence that spinal manipulation is no more effective than sham spinal manipulation for the treatment of infantile colic [254]. 
- Inconclusive evidence in a favorable direction regarding the effectiveness of cranial osteopathic manual treatment and massage for the treatment of infantile colic [255,257].

Other effective non-invasive physical treatments or patient education

Reduce stimulation, herbal tea, and trial of hypoallergenic formula milk $[258,259]$

\section{Nocturnal Enuresis}

\section{Definition}

Nocturnal enuresis is defined as the involuntary loss of urine at night, in the absence of organic disease, at an age when a child could reasonably be expected to be dry (typically at the age of five) [260].

Diagnosis

The diagnosis of nocturnal enuresis is derived mainly from the patient's history given the absence of other organic causes including congenital or acquired defects of the central nervous system. Psychological factors can be contributory in some children requiring proper assessment and treatment [261].

\section{Evidence base for manual treatment}

\section{Systematic reviews (most recent)}

Since 2005, two systematic reviews, one a Cochrane review, evaluating the benefit of manual therapy for nocturnal enuresis were published [230,262]. The systematic reviews included a total of two randomized clinical trials $[263,264]$. Both of the included trials examined the use of spinal manipulation for nocturnal enuresis. Both reviews concluded there is insufficient evidence to make conclusions about the effectiveness of spinal manipulation for the treatment of enuresis.

\section{Evidence-based clinical guidelines}

None addressing manual therapy as a treatment option

\section{Randomized clinical trials not included in above}

None

Evidence Summary (See Figure 7)

- Inconclusive evidence in a favorable direction regarding the effectiveness of chiropractic care for the treatment of enuresis [230,262].

Other effective non-invasive physical treatments or patient education

Education, simple behavioral interventions, and alarm treatment [265]

\section{Otitis Media}

Definition

Otitis media is characterized by middle ear inflammation which can exist in an acute or chronic state and can occur with or without symptoms [266].

\section{Diagnosis}

Diagnosis of otitis media relies on otoscopic signs and symptoms consistent with a purulent middle ear effusion in association with systemic signs of illness [266].

\section{Evidence base for manual treatment \\ Systematic reviews (most recent)}

Hawk et al [230] found promising evidence for the potential benefit of spinal manipulation/mobilization procedures for children with otitis media. This was based on one trial [267]. Two other reviews specifically addressed spinal manipulation by chiropractors for nonmusculoskeletal [247] and pediatric [248] conditions. Both found insufficient evidence to comment on manual treatment effectiveness or ineffectiveness for otitis media.

\section{Evidence-based clinical guidelines}

The American Academy of Pediatrics 2004 guidelines on the diagnosis and management of acute otitis media [268] concluded no recommendation for complementary and alternative medicine for the treatment of acute otitis media can be made due to limited data.

\section{Recent randomized clinical trials not included in above}

Wahl et al investigated the efficacy of osteopathic manipulative treatment with and without Echinacea compared to sham and placebo for the treatment of otitis media [269]. The study found that a regimen of up to five osteopathic manipulative treatments does not significantly decrease the risk of acute otitis media episodes. This study had a high risk of bias.

\section{Evidence Summary (See Figure 7)}

- Inconclusive evidence in an unclear direction regarding the effectiveness of osteopathic manipulative therapy for otitis media [267,269].

\section{Other effective non-invasive physical treatments or patient} education

Patient education and "watch and wait" approach for 72 hours for acute otitis media [266,268]

\section{Hypertension}

Definition

Hypertension is defined as the sustained elevation of systolic blood pressure over $140 \mathrm{mmHg}$, diastolic blood pressure over $90 \mathrm{~mm} \mathrm{Hg}$, or both [270,271].

\section{Diagnosis}

Diagnosis of hypertension is made by the physical exam, specifically sphygmomanometry. The patient's history, clinical exam and laboratory tests help identify potential etiologies [270,271].

Evidence base for manual treatment Systematic reviews (most recent)

Since 2007, one systematic review evaluating the benefit of manual therapy for hypertension has been published 
(Hawk et al) [230]. Two RCTs evaluating the effectiveness of manual therapy for the treatment of stage I hypertension were included in this systematic review $[272,273]$. One of the included trials evaluated the use of spinal manipulation [272] and the other evaluated the use of instrument assisted spinal manipulation [273]. The review found no evidence of effectiveness for spinal manipulation.

\section{Evidence-based clinical guidelines}

None addressing the use of manual therapy

Recent randomized clinical trials not included in above

A study by Bakris et al [274] found NUCCA upper cervical manipulation to be more effective than sham manipulation in lowering blood pressure in patients with Stage I hypertension. This study had a high risk of bias.

\section{Evidence Summary (See Figure 6)}

- Moderate quality evidence that diversified spinal manipulation is not effective when added to a diet in the treatment of stage I hypertension [272].

- Inconclusive evidence in a favorable direction regarding upper cervical NUCCA manipulation for stage I hypertension [274].

- Inconclusive evidence in an unclear direction regarding instrument assisted spinal manipulation for hypertension [273].

Other effective non-invasive physical treatments or patient education

Advice on lifestyle interventions including diet, exercise, moderate alcohol consumption and smoking cessation [270,271]

Relaxation therapies including biofeedback, meditation, or muscle relaxation [271]

\section{Dysmenorrhea \\ Definition}

Dysmenorrhea is defined as painful menstrual cramps of uterine origin. Dysmenorrhea is grouped into two categories, primary and secondary dysmenorrhea. Secondary dysmenorrhea is painful menstruation associated with a pelvic pathology like endometriosis, while primary dysmenorrhea is painful menstruation in the absence of pelvic disease [275].

\section{Diagnosis}

Diagnosis of primary dysmenorrhea is made from the patient's history. Diagnosis of secondary dysmenorrhea requires further investigation including a pelvic exam and potential ultrasound or laparoscopy [275].

\section{Evidence base for manual treatment}

\section{Systematic reviews (most recent)}

We identified two systematic reviews evaluating the benefit of manual therapy for dysmenorrhea $[230,276]$. Five studies evaluating the effectiveness of manual therapy for the treatment of dysmenorrhea were included in the systematic reviews [277-281]. Four of the included trials examined the use of spinal manipulation [278-281] and one examined the use of osteopathic manipulative techniques [277]. Based on these trials, the Cochrane review by Proctor et al concluded there is no evidence to suggest that spinal manipulation is effective in the treatment of primary and secondary dysmenorrhea [276]. The review by Hawk et al concluded the evidence was equivocal regarding chiropractic care for dysmenorrhea [230].

\section{Evidence-based clinical guidelines}

We identified consensus guidelines from the Society of Obstetricians and Gynecologists of Canada (SOGC) published in 2005 which included an assessment of manual treatment for primary dysmenorrhea. The authors concluded there is no evidence to support spinal manipulation as an effective treatment for primary dysmenorrhea [275].

\section{Recent randomized clinical trials not included in above}

None

\section{Evidence Summary (See Figure 7)}

- Moderate quality evidence that spinal manipulation is no more effective than sham manipulation in the treatment of primary dysmenorrhea [276,281].

Other effective non-invasive physical treatments or patient education

High frequency TENS [275]

\section{Premenstrual Syndrome \\ Definition}

Premenstrual syndrome is defined as distressing physical, behavioral, and psychological symptoms, in the absence of organic or underlying psychiatric disease, which regularly recurs during the luteal phase of the menstrual cycle and disappears or significantly regresses by the end of menstruation and is associated with impairment in daily functioning and/or relationships [282,283].

\section{Diagnosis}

Diagnosis of premenstrual syndrome is made through patient history and the use of a patient diary over two menstrual cycles [282,283].

\section{Evidence base for manual treatment Systematic reviews (most recent)}

Since 2007, three systematic reviews evaluating the benefit of manual therapy for premenstrual syndrome have been published [230,284,285]. Three RCTs evaluating the effectiveness of manual therapy for the treatment of premenstrual syndrome were included in the reviews [286-288]. The included trials examined different forms of manual therapy including spinal manipulation [286], massage therapy [287], and reflexology [288]. Overall, 
the reviews concluded that the evidence is "not promising" [284], "equivocal" [230], and that high quality studies are needed to draw firm conclusions [284,285].

\section{Evidence-based clinical guidelines}

None discussing manual therapy

Recent randomized clinical trials not included in above None

\section{Evidence Summary (See Figure 7)}

- Inconclusive evidence in a favorable direction regarding the effectiveness of reflexology and massage therapy for the treatment of premenstrual syndrome [230].

- Inconclusive evidence in an unclear direction regarding the effectiveness of spinal manipulation for the treatment of premenstrual syndrome [230].

Other effective non-invasive physical treatments or patient education

Cognitive behavioral therapy [282]

\section{Discussion}

\section{Making claims}

There are two important questions underlying the medical and media debate surrounding the scope of chiropractic care and claims regarding its effectiveness particularly for non-musculoskeletal conditions: 1) should health professionals be permitted to use generally safe but as yet unproven methods? 2) What claims, if any, can and should be made with respect to the potential value of unproven treatments?

In response to the first question, a reasonable answer is "yes" given that professionals operate within the context of EBH, where it is acknowledged what is known today, might change tomorrow. It requires flexibility born of intellectual honesty that recognizes one's current clinical practices may not really be in the best interests of the patient and as better evidence emerges, clinicians are obligated to change. Further, where evidence is absent, they are open to promoting the development of new knowledge that expands understanding of appropriate health care delivery.

In response to the second question, no claims of efficacy/effectiveness should be made for which there isn't sufficient evidence. Unsubstantiated claims can be dangerous to patient health [289]. We maintain the best evidence for efficacy/effectiveness that meets society's standards comes from well-designed RCTs. While other study designs and clinical observations do offer insight into the plausibility and potential value of treatments, the concepts of plausibility and evidence of efficacy/effectiveness should not be confused when making claims.

\section{Clinical Experience versus Clinical effectiveness}

Why is it that the results of RCTs often do not confirm the results observed in clinical practice? There are several reasons. One of the problems is that both the provider and the patient are likely to interpret any improvement as being solely a result of the intervention being provided. However this is seldom the case. First, the natural history of the disorder (for example. acute LBP) is expected to partially or completely resolve by itself regardless of treatment. Second, the phenomenon of regression to the mean often accounts for some of the observed improvement in the condition. Regression to the mean is a statistical phenomenon associated with the fact that patients often present to the clinic or in clinical trials at a time where they have relatively high scores on severity outcome measures. If measured repeatedly before the commencement of treatment the severity scores usually regress towards lower more normal average values [290].

Additionally, there is substantial evidence to show that the ritual of the patient practitioner interaction has a therapeutic effect in itself separate from any specific effects of the treatment applied. This phenomenon is termed contextual effects $[1,291]$. The contextual or, as it is often called, non-specific effect of the therapeutic encounter can be quite different depending on the type of provider, the explanation or diagnosis given [292], the provider's enthusiasm, and the patient's expectations [293-298]. Some researchers have suggested that relying on evidence from RCTs and systematic reviews of RCTs is not adequate to determine whether a treatment is effective or not. The main issue, they contend, is that the intervention when studied in RCTs is too highly protocolized and does not reflect what is going on in clinical practice [230]. They advocate a whole systems research approach that more accurately represents the entire clinical encounter. When using this perspective and systematically synthesizing the literature regarding chiropractic treatment of non-musculoskeletal conditions, also reviewed in this report, they conclude, for example that chiropractic is beneficial to patients with asthma and to children with infantile colic [230]. This conclusion is at odds with the evidence summaries found in this report. We submit that whole systems research approach in this instance is clouding the interpretation of the literature regarding effectiveness as it relates to making claims, and incorrectly giving the consumer the impression that chiropractic care shows effectiveness over and above the contextual effects as it relates to the two examples above.

In a placebo-controlled RCT the question is: does the treatment provided have a specific effect over and above the contextual or non-specific effects. The result of such a trial may show that there is no important difference between the active intervention and the sham intervention. However, the patients may exhibit clinically important changes from baseline in both groups and thus the 
outcome would be consistent with what clinicians observe in their practice. An example of this is the results of the pragmatic placebo controlled RCT on chiropractic co-management of chronic asthma in adults (care delivered by experienced chiropractors consistent with normal clinical practice), which showed that patients improved equally during both the active and the sham intervention phases of the trial [231].

\section{The Pieces of The Evidence-Based Healthcare Puzzle}

It is essential to recognize what each piece of the EBH puzzle offers. Patient values and preferences do not provide sound evidence of a treatment's effectiveness and may be misleading. A patient can be satisfied with a treatment, but it still may not be effective. The clinician's observations, if well documented, can attest to patient improvement while under care and encourage perception of a treatment's clinical plausibility. However, the narrow focus of attention under non-systematic observations common to practice experience tends to obscure other factors influencing case outcome. Similarly, EBH can be flawed, not because it fails to be scientific, but because-like all sciences-it imports the biases of researchers and clinicians [299]. Well-performed clinical research however, does provide evidence for claims that a treatment is effective when the results are consistently applied to relevant patients. This is because of its reliance on methods for systematic observation and efforts to minimize bias.

Other authors' work has been used to argue that a range of study types should be included when evaluating a treatment's efficacy/effectiveness (case series, etc.) $[230,300]$. We maintain the best evidence that rises to societal standards to support claims of efficacy/effectiveness comes from well-designed RCTs. This is largely due to the powerful effect of successful randomization and design factors intended to minimize bias (all which help ensure that the results are due to the intervention and not some other known or unknown factor). Other evidence may be useful to inform treatment options when conditions for individual patients are not consistent with the best evidence or when better evidence is unavailable [11]. Other types of research are more appropriate for answering related questions including, but not limited to, safety or mechanistic plausibility. This can lead to the refinement of interventions, inform the design of clinical trials, and aid in the interpretation of clinical observations. Similarly, clinical data from epidemiological studies, case reports, and case series can suggest that a treatment is clinically plausible. That is, clinical observations demonstrate that it is possible that an intervention is effective. However, a gain in plausibility, biological or clinical, does NOT constitute proof of a treatment's efficacy in human populations. Conversely lack of proof (as demonstrated through well performed randomized clinical trials) does not exclude plausibility [301,302].

Research on systematic reviews have taught us that individual studies can often lead to a conclusion very different from that of a systematic analysis of all available studies [3]. Moreover, the scientific process is a systematic means of self-correcting investigations that classically begin with observations and hypotheses that support plausibility and/or mechanisms. Ideally, these precede and inform the conduct of RCTs under conditions most likely to yield clear results, often referred to as efficacy studies. Separately, studies that emulate general practice conditions may be used to develop an understanding of effectiveness. Historically, the modern investigation of manual treatment methods represents an aberration in this process. With the advent of social support and funding for research at the end of the $20^{\text {th }}$ Century, there was an underlying presumption that the long-term practice of these methods provided a sound clinical wisdom on which to ground RCTs, bypassing mechanistic studies. The early emphasis on clinical trials has illuminated the gaps in understanding of appropriate indications for treatment, dosage and duration of care, consistency of treatment application, and the appropriate outcome measures to monitor results [11]. In response, funding agencies in North America have renewed research emphasis on the potential mechanisms of effect [303]. Data from this work is expected to inform future clinical research questions, and subsequently lead to well-grounded studies that are likely to yield more complete evidence regarding appropriate and effective care.

\section{Safety of Manual Treatment}

Choosing an intervention should always be tempered by the risk of adverse events or harm. Adverse events associated with manual treatment can be classified into two categories: 1) benign, minor or non-serious and 2) serious. Generally those that are benign are transient, mild to moderate in intensity, have little effect on activities, and are short lasting. Most commonly, these involve pain or discomfort to the musculoskeletal system. Less commonly, nausea, dizziness or tiredness are reported. Serious adverse events are disabling, require hospitalization and may be life-threatening. The most documented and discussed serious adverse event associated with spinal manipulation (specifically to the cervical spine) is vertebrobasilar artery (VBA) stroke [304,305]. Less commonly reported are serious adverse events associated with lumbar spine manipulation, including lumbar disc herniation and cauda equina syndrome [304].

Estimates of serious adverse events as a result of spinal manipulation have been uncertain and varied. 
Much of the available evidence has been relatively poor due to challenges in establishing accurate risk estimates for rare events. Such estimates are best derived from sound population based studies, preferably those that are prospective in nature $[304,306]$.

Estimates of VBA stroke subsequent to cervical spine manipulation range from one event in 200,000 treatments to one in several million $[307,308]$. In a subsequent landmark population-based study, Cassidy et al [309] revisited the issue using case-control and casecrossover designs to evaluate over 100 million personyears of data. The authors confirmed that VBA stroke is a very rare event in general. They stated, "We found no evidence of excess risk of VBA stroke associated with chiropractic care compared to primary care." They further concluded, "The increased risk of VBA stroke associated with chiropractic and PCP (primary care physician) visits is likely due to patients with headache and neck pain from VBA dissection seeking care before their stroke." In regards to benign adverse reactions, cervical spine manipulation has been shown to be associated with an increased risk when compared to mobilization [55,310,311].

Appropriately, the risk-benefit of cervical spine manipulation has been debated [304,305]. As anticipated, new research can change what is known about the benefit of manual treatment for neck pain. Currently, the evidence suggests that it has some benefit [55]. It has been suggested that the choice between mobilization and manipulation should be informed by patient preference [55].

Estimates of cervical or lumbar disc herniation are also uncertain, and are based on case studies and case series. It has been estimated that the risk of a serious adverse event, including lumbar disc herniation is approximately 1 per million patient visits [312]. Cauda equina syndrome is estimated to occur much less frequently, at 1 per several million visits [312-314].

\section{Safety of Manual Treatment in Children}

The true incidence of serious adverse events in children as a result of spinal manipulation remains unknown. A systematic review published in 2007 identified 14 cases of direct adverse events involving neurologic or musculoskeletal events, nine of which were considered serious (eg. subarachnoid hemorrhage, paraplegia, etc.) [315]. Another 20 cases of indirect adverse events were identified (delayed diagnosis, inappropriate application of spinal manipulation for serious medical conditions). The review authors note that case reports and case series are a type of "passive" surveillance, and as such don't provide information regarding incidence. Further, this type of reporting of adverse events is recognized to underestimate true risk [315-317].
Importantly, the authors postulate that a possible reason for incorrect diagnosis (for example. delayed diagnosis, inappropriate treatment with spinal manipulation) is due to lack of sufficient pediatric training. They cite their own survey [318] which found that in a survey of 287 chiropractors and osteopaths, $78 \%$ reported one semester or less of formal pediatric education and $72 \%$ received no pediatric clinical training. We find this particularly noteworthy.

\section{Limitations of the Report Conclusions}

The conclusions in this report regarding the strength of evidence of presence or absence of effectiveness are predicated on the rules chosen for which there are no absolute standards. Different evidence grading systems and rules regarding impact of study quality may lead to different conclusions. However, we have applied a synthesis methodology consistent with the latest recommendations from authoritative organizations involved in setting standards for evidence synthesis. Although we used a comprehensive literature search strategy we may not have identified all relevant RCTs, guidelines, and technology reports. Conditions for which this report concludes the evidence currently shows manual treatment to be effective or even ineffective, sometimes rests on a single RCT with adequate statistical power and low risk of bias. Additional high quality RCTs on the same topics have a substantial likelihood of changing the conclusions. Including only English language reviews and trials may be considered another limitation of this report leading to language bias; however, the impact of excluding non-English trials from metaanalyses and systematic reviews is conflicting [319,320], and the incidence of randomized trials published in non-English journals is declining [321]. Another potential limitation of this report is the lack of critical appraisal of the systematic reviews and clinical guidelines included in the report. Systematic reviews and clinical guidelines can differ widely in methodologic quality and risk of bias [322]. While critical appraisal of the included reviews and guidelines would be ideal, it was beyond the scope of the present report. When drawing conclusions about relative effectiveness of different forms of manual treatments it is acknowledged that it has usually not been possible to isolate or quantify the specific effects of the interventions from the non-specific (contextual) effect of patient-provider interaction [291]. It was beyond the scope of this report to assess the magnitude of the effectiveness of the different manual therapies relative to the therapies to which comparisons were made. However, if moderate or high quality evidence of effectiveness was established the therapy was interpreted as a viable treatment option, but not necessarily the 
most effective treatment available. We recognize that findings from studies using a nonrandomized design (for example. observational studies, cohort studies, prospective clinical series and case reports) can yield important preliminary evidence on potential mechanisms and plausibility of treatment effects. However, the primary purpose of this report is to summarize the results of studies designed to specifically address treatment efficacy and effectiveness from which claims of clinical utility, consistent with that literature, may be considered defensible. Therefore, the evidence base on the effects of care was restricted to RCTs.

\section{Conclusions}

Spinal manipulation/mobilization is effective in adults for acute, subacute, and chronic low back pain; for migraine and cervicogenic headache; cervicogenic dizziness; and a number of upper and lower extremity joint conditions. Thoracic spinal manipulation/mobilization is effective for acute/subacute neck pain, and, when combined with exercise, cervical spinal/manipulation is effective for acute whiplash-associated disorders and for chronic neck pain. The evidence is inconclusive for cervical manipulation/mobilization alone for neck pain of any duration, and for any type of manipulation/mobilization for mid back pain, sciatica, tension-type headache, coccydynia, temporomandibular joint disorders, fibromyalgia, premenstrual syndrome, and pneumonia in older adults. Spinal manipulation is not effective for asthma and dysmenorrhea when compared to sham manipulation, or for Stage 1 hypertension when added to an antihypertensive diet. For children, the evidence is inconclusive regarding the effectiveness of spinal manipulation/mobilization for otitis media and enuresis, but shows it is not effective for infantile colic and for improving lung function in asthma when compared to sham manipulation.

The evidence regarding massage shows that for adults it is an effective treatment option for chronic LBP and chronic neck pain. The evidence is inconclusive for knee osteoarthritis, fibromyalgia, myofascial pain syndrome, migraine headache, and premenstrual syndrome. For children, the evidence is inconclusive for asthma and infantile colic.

Additional file 1: The literature search strategy.

Click here for file

[http://www.biomedcentral.com/content/supplementary/1746-1340-18-3S1.DOC ]

Additional file 2: Includes the criteria used for evaluating risk of bias from randomized controlled trials not included within systematic reviews, evidence based guidelines, or health technology assessments. Click here for file

[http://www.biomedcentral.com/content/supplementary/1746-1340-18-3S2.DOC ]

\section{Acknowledgements}

The UK General Chiropractic Council provided the funding for this scientific evidence report.

Della Shupe, librarian at NWHSU, is acknowledged for helping design and perform the detailed search strategy used for the report.

\section{Author details}

${ }^{1}$ Northwestern Health Sciences University, 2501 W 84th St, Bloomington, MN, USA. ${ }^{2}$ University of Western States, 2900 NE 132nd Ave, Portland, OR, USA ${ }^{3}$ Canadian Memorial Chiropractic College, 6100 Leslie St, North York, ON, Canada. ${ }^{4}$ McMaster University, 1280 Main St W, Hamilton, ON, Canada.

\section{Authors' contributions}

GB was responsible for the methodology used to select and summarize the evidence, for organizing and participating in the analysis of the evidence and formulating conclusions and drafting and finalizing the report $\mathrm{MH}$ participated in analyzing the evidence and formulating conclusions for the majority of the musculoskeletal conditions and the different types of headache.

RE participated in analyzing the evidence and formulating conclusion for part of the musculoskeletal and non-musculoskeletal conditions and providing substantial input to the background and discussion sections. $\mathrm{BL}$ was responsible for retrieving the research articles and providing draft summary statements for all conditions as well as participating in drafting and proof reading the manuscript.

$J T$ was responsible for conceiving and drafting the section on translation of research into action and providing substantial input to the background and discussion sections.All authors have read and approved the final manuscript.

\section{Competing interests}

All authors are trained as doctors of chiropractic but are now full time professional researchers.

Received: 26 November 2009

Accepted: 25 February 2010 Published: 25 February 2010

\section{References}

1. Goldberg M: On evidence and evidence-based medicine: lessons from the philosophy of science. Soc Sci Med 2006, 62:2621-2632.

2. Nelson LH: Epistemological communities. In Feminist epistemologies Alcoff, Potter E 1993, 121-160

3. Lavis JN, Robertson D, Woodside JM, McLeod CB, Abelson J: How can research organizations more effectively transfer research knowledge to decision makers?. Milbank Q 2003, 81:221-222.

4. Straus SE, Tetroe J, Graham I: Defining knowledge translation. CMAJ 2009, 181:165-168

5. Muir Gray JA: Evidence Based Healthcare How to make Health Policy and Management Decisions Harcourt Publishers Limited, 2001.

6. Guyatt G, Cook D, Haynes B: Evidence based medicine has come a long way. BMJ 2004, 329:990-991.

7. Reilly BM: The essence of EBM. BMJ 2004, 329:991-992

8. Lambert H: Accounting for EBM: notions of evidence in medicine. Soc Sci Med 2006, 62:2633-2645.

9. Davey Smith G, Egger M: Incommunicable knowledge? Interpreting and applying the results of clinical trials and meta-analyses. J Clin Epidemiol 1998, 51:289-295.

10. Schatter A, Fletcher $\mathrm{RH}$ : Research evidence and the individual patient. Quarterly Journal of Medicine 2003, 96:1-5.

11. Triano JJ: What constitutes evidence for best practice?. J Manipulative Physiol Ther 2008, 31:637-643.

12. Greenhalgh T, Hurwitz B: Narrative based medicine; Why study narrative? BMJ 1999, 318:48-50.

13. Hope T: Evidence-based patient choice and psychiatry. Evid Based Ment Health 2002, 5:100-101.

14. Evidence-based patient choice: Inevitable or impossible? Oxford University Press 2001.

15. Shaughnessy AF, Slawson DC, Becker L: Clinical jazz: harmonizing clinical experience and evidence-based medicine. J Fam Pract 1998, 47:425-428.

16. Straus SE: What's the E for EBM?. BMJ 2004, 328:535-536.

17. Marmot MG: Evidence based policy or policy based evidence?. BMJ 2004, 328:906-907. 
18. Chou R, Huffman LH: Nonpharmacologic therapies for acute and chronic low back pain: a review of the evidence for an American Pain Society/ American College of Physicians clinical practice guideline. Ann Intern Med 2007, 147:492-504.

19. Haynes RB, Devereaux PJ, Guyatt GH: Physicians' and patients' choices in evidence based practice. BMJ 2002, 324:1350.

20. Gordon EJ: The political contexts of evidence-based medicine: policymaking for daily hemodialysis. Soc Sci Med 2006, 62:2707-2719.

21. Savigny $P$, Watson $P$, Underwood M: Early management of persistent nonspecific low back pain: summary of NICE guidance. BMJ 2009, 338:b1805.

22. Chou R, Qaseem A, Snow V, Casey D, Cross JT Jr, Shekelle P, et al: Diagnosis and treatment of low back pain: a joint clinical practice guideline from the American College of Physicians and the American Pain Society. Ann Intern Med 2007, 147:478-491.

23. Airaksinen O, Brox Jl, Cedraschi C, Hildebrandt J, Klaber-Moffett J, Kovacs F, et al: Chapter 4. European guidelines for the management of chronic nonspecific low back pain. Eur Spine J 2006, 15(Suppl 2):S192-S300.

24. van Tulder M, Becker A, Bekkering T, Breen A, Del Real MT, Hutchinson A, et al: Chapter 3. European guidelines for the management of acute nonspecific low back pain in primary care. Eur Spine J 2006, 15(Suppl 2): S169-S191.

25. Assendelft WJ, Morton SC, Yu El, Suttorp MJ, Shekelle PG: Spinal manipulative therapy for low back pain. Cochrane Database Syst Rev 2004, CD000447.

26. van Tulder MW, Koes B, Malmivaara A: Outcome of non-invasive treatment modalities on back pain: an evidence-based review. Eur Spine J 2006, 15(Suppl 1):S64-S81.

27. Lawrence DJ, Meeker W, Branson R, Bronfort G, Cates JR, Haas M, et al: Chiropractic management of low back pain and low back-related leg complaints: a literature synthesis. J Manipulative Physiol Ther 2008, 31:659-674.

28. Bronfort G, Haas M, Evans R, Kawchuk G, Dagenais S: Evidence-informed management of chronic low back pain with spinal manipulation and mobilization. Spine J 2008, 8:213-225.

29. Bronfort G, Haas M, Evans RL, Bouter LM: Efficacy of spinal manipulation and mobilization for low back pain and neck pain: a systematic review and best evidence synthesis. Spine J 2004, 4:335-356.

30. Furlan AD, Imamura M, Dryden T, Irvin E: Massage for Low Back Pain: An Updated Systematic Review Within the Framework of the Cochrane Back Review Group. Spine 2009, 34:1669-1684.

31. National Institute for Health and Clinical Excellence: Low back pain: Early management of persistent non-specific low back pain. Clinical guideline 2009, 88.

32. Hallegraeff JM, de Greef M, Winters JC, Lucas C: Manipulative therapy and clinical prediction criteria in treatment of acute nonspecific low back pain. Percept Mot Skills 2009, 108:196-208.

33. Rasmussen J, Laetgaard J, Lindecrona AL, Qvistgaard E, Bliddal H: Manipulation does not add to the effect of extension exercises in chronic low-back pain (LBP). A randomized, controlled, double blind study. Joint Bone Spine 2008, 75:708-713.

34. Little P, Lewith G, Webley F, Evans M, Beattie A, Middleton K, et al: Randomised controlled trial of Alexander technique lessons, exercise, and massage (ATEAM) for chronic and recurrent back pain. Br J Sports Med 2008, 42:965-968.

35. Wilkey A, Gregory M, Byfield D, McCarthy PW: A comparison between chiropractic management and pain clinic management for chronic lowback pain in a national health service outpatient clinic. J Altern Complement Med 2008, 14:465-473.

36. Bogefeldt J, Grunnesjo MI, Svardsudd K, Blomberg S: Sick leave reductions from a comprehensive manual therapy programme for low back pain: the Gotland Low Back Pain Study. Clin Rehabil 2008, 22:529-541.

37. Hancock MJ, Maher CG, Latimer J, McLachlan AJ, Cooper CW, Day RO, et al: Assessment of diclofenac or spinal manipulative therapy, or both, in addition to recommended first-line treatment for acute low back pain: a randomised controlled trial. Lancet 2007, 370:1638-1643.

38. Ferreira ML, Ferreira PH, Latimer J, Herbert RD, Hodges PW, Jennings MD, et al: Comparison of general exercise, motor control exercise and spinal manipulative therapy for chronic low back pain: A randomized trial. Pain 2007, 131:31-37.
39. Eisenberg DM, Post DE, Davis RB, Connelly MT, Legedza AT, Hrbek AL, et al: Addition of choice of complementary therapies to usual care for acute low back pain: a randomized controlled trial. Spine 2007, 32:151-158.

40. Hondras MA, Long CR, Cao Y, Rowell RM, Meeker WC: A randomized controlled trial comparing 2 types of spinal manipulation and minimal conservative medical care for adults 55 years and older with subacute or chronic low back pain. J Manipulative Physiol Ther 2009, 32:330-343.

41. Mohseni-Bandpei MA, Critchley J, Staunton T, et al: A prospective randomised controlled trial of spinal manipulation and ultrasound in the treatment of chronic low back pain. Physiotherapy 2006, 92:34-42.

42. Beyerman KL, Palmerino MB, Zohn LE, Kane GM, Foster KA: Efficacy of treating low back pain and dysfunction secondary to osteoarthritis: chiropractic care compared with moist heat alone. J Manipulative Physiol Ther 2006, 29:107-114.

43. Poole $H$, Glenn S, Murphy P: A randomised controlled study of reflexology for the management of chronic low back pain. Eur J Pain 2007, 11:878-887.

44. Zaproudina N, Hietikko T, Hanninen OO, Airaksinen O: Effectiveness of traditional bone setting in treating chronic low back pain: a randomised pilot trial. Complement Ther Med 2009, 17:23-28.

45. Australian Acute Musculoskeletal Pain Guidelines Group: Evidence-Based Management of Acute Musculoskeletal Pain. Bowen Hills QLD, Australian Academic Press Pty. Ltd 2003.

46. Bussieres AE, Taylor JA, Peterson C: Diagnostic imaging practice guidelines for musculoskeletal complaints in adults-an evidence-based approachpart 3: spinal disorders. J Manipulative Physiol Ther 2008, 31:33-88.

47. Schiller L: Effectiveness of spinal manipulative therapy in the treatment of mechanical thoracic spine pain: a pilot randomized clinical trial. J Manipulative Physiol Ther 2001, 24:394-401.

48. Cleland JA, Childs JD, McRae M, Palmer JA, Stowell T: Immediate effects of thoracic manipulation in patients with neck pain: a randomized clinical trial. Man Ther 2005, 10:127-135.

49. Savolainen A, Ahlberg J, Nummila H, Nissinen M: Active or passive treatment for neck-shoulder pain in occupational health care? A randomized controlled trial. Occup Med (Lond) 2004, 54:422-424.

50. Allison GT, Nagy BM, Hall T: A randomized clinical trial of manual therapy for cervico-brachial pain syndrome - a pilot study. Man Ther 2002, 7:95-102.

51. Bergman GJ, Winters JC, Groenier KH, Pool JJ, Meyboom-de Jong B, Postema $\mathrm{K}$, et al: Manipulative therapy in addition to usual medical care for patients with shoulder dysfunction and pain: a randomized, controlled trial. Ann Intern Med 2004, 141:432-439.

52. Winters JC, Sobel JS, Groenier KH, Arendzen HJ, Meyboom-de Jong B: Comparison of physiotherapy, manipulation, and corticosteroid injection for treating shoulder complaints in general practice: randomised, single blind study. BMJ 1997, 314:1320-1325.

53. Winters JC, Jorritsma W, Groenier KH, Sobel JS, Meyboom-de Jong B, Arendzen $\mathrm{HJ}$ : Treatment of shoulder complaints in general practice: long term results of a randomised, single blind study comparing physiotherapy, manipulation, and corticosteroid injection. BMJ 1999, 318:1395-1396.

54. Haldeman S, Carroll L, Cassidy D, Schubert J, Nygren A: The Bone and Joint Decade 2000-2010 Task Force on Neck Pain and Its Associated Disorders: executive summary. Spine 2008, 33:S5-S7.

55. Hurwitz EL, Carragee EJ, Velde van der G, Carroll LJ, Nordin M, Guzman J, et al: Treatment of neck pain: noninvasive interventions: results of the Bone and Joint Decade 2000-2010 Task Force on Neck Pain and Its Associated Disorders. J Manipulative Physiol Ther 2009, 32:S141-S175.

56. Childs JD, Cleland JA, Elliott JM, Teyhen DS, Wainner RS, Whitman JM, et al: Neck pain: Clinical practice guidelines linked to the International Classification of Functioning, Disability, and Health from the Orthopedic Section of the American Physical Therapy Association. J Orthop Sports Phys Ther 2008, 38:A1-A34.

57. Ernst E: Chiropractic spinal manipulation for neck pain: a systematic review. J Pain 2003, 4:417-421.

58. Gross AR, Hoving JL, Haines TA, Goldsmith $\mathrm{CH}$, Kay T, Aker P, et al: Manipulation and mobilisation for mechanical neck disorders. Cochrane Database Syst Rev 2004, CD004249. 
59. Vernon HT, Humphreys BK, Hagino CA: A systematic review of conservative treatments for acute neck pain not due to whiplash. $J$ Manipulative Physiol Ther 2005, 28:443-448.

60. Ezzo J, Haraldsson BG, Gross AR, Myers CD, Morien A, Goldsmith $C H$, et al: Massage for mechanical neck disorders: a systematic review. Spine (Phila Pa 1976) 2007, 32:353-362.

61. Hakkinen A, Salo P, Tarvainen U, Wiren K, Ylinen J: Effect of manual therapy and stretching on neck muscle strength and mobility in chronic neck pain. J Rehabil Med 2007, 39:575-579.

62. Gonzalez-Iglesias J, Fernandez-de-las-Penas C, Cleland JA, GutierrezVega MR: Thoracic spine manipulation for the management of patients with neck pain: a randomized clinical trial. J Orthop Sports Phys Ther 2009, 39:20-27.

63. Gonzalez-lglesias J, Fernandez-de-las-Penas C, Cleland JA, AlburquerqueSendin F, Palomeque-del-Cerro L, Mendez-Sanchez R: Inclusion of thoracic spine thrust manipulation into an electro-therapy/thermal program for the management of patients with acute mechanical neck pain: a randomized clinical trial. Man Ther 2009, 14:306-313.

64. Walker MJ, Boyles RE, Young BA, Strunce JB, Garber MB, Whitman JM, et al: The effectiveness of manual physical therapy and exercise for mechanical neck pain: a randomized clinical trial. Spine (Phila Pa 1976) 2008, 33:2371-2378.

65. Cleland JA, Glynn P, Whitman JM, Eberhart SL, MacDonald C, Childs JD: Short-term effects of thrust versus nonthrust mobilization/manipulation directed at the thoracic spine in patients with neck pain: a randomized clinical trial. Phys Ther 2007, 87:431-440

66. Fernandez-de-las-Penas C, Fernandez-Carnero J, Fernandez A, LomasVega R, Miangolarra-Page JC: Dorsal Manipulation in Whiplash Injury Treatment: A Randomized Controlled Trial. Journal of Whiplash \& Related Disorders 2004, 3:55-72.

67. Zaproudina N, Hanninen OO, Airaksinen O: Effectiveness of traditional bone setting in chronic neck pain: randomized clinical trial. Manipulative Physiol Ther 2007, 30:432-437

68. Sherman KJ, Cherkin DC, Hawkes RJ, Miglioretti DL, Deyo RA: Randomized trial of therapeutic massage for chronic neck pain. Clin J Pain 2009, 25:233-238.

69. Patel R, Appannagari A, Whang PG: Coccydynia. Curr Rev Musculoskelet Med 2008, 1:223-226

70. Maigne JY, Chatellier G, Faou ML, Archambeau M: The treatment of chronic coccydynia with intrarectal manipulation: a randomized controlled study. Spine (Phila Pa 1976) 2006, 31:E621-E627.

71. Bussieres AE, Peterson C, Taylor JA: Diagnostic imaging guideline for musculoskeletal complaints in adults-an evidence-based approach-part 2: upper extremity disorders. J Manipulative Physiol Ther 2008, 31:2-32.

72. Green S, Buchbinder R, Hetrick S: Physiotherapy interventions for shoulder pain. Cochrane Database Syst Rev 2003, CD004258.

73. Desmeules F, Cote CH, Fremont P: Therapeutic exercise and orthopedic manual therapy for impingement syndrome: a systematic review. Clin $J$ Sport 2003, 13:176-182.

74. Bang MD, Deyle GD: Comparison of supervised exercise with and without manual physical therapy for patients with shoulder impingement syndrome. J Orthop Sports Phys Ther 2000, 30:126-137.

75. Bulgen DY, Binder Al, Hazleman BL, Dutton J, Roberts S: Frozen shoulder: prospective clinical study with an evaluation of three treatment regimens. Ann Rheum Dis 1984, 43:353-360.

76. Conroy DE, Hayes KW: The effect of joint mobilization as a component of comprehensive treatment for primary shoulder impingement syndrome. J Orthop Sports Phys Ther 1998, 28:3-14.

77. Nicholson GG: The effects of passive joint mobilization on pain and hypomobility associated with adhesive capsulitis of the shoulder. $J$ Orthop Sports Phys Ther 1985, 6:238-246.

78. Winters JC, Jorritsma W, Groenier KH, Sobel JS, Meyboom-de Jong B, Arendzen $\mathrm{HJ}$ : Treatment of shoulder complaints in general practice: long term results of a randomised, single blind study comparing physiotherapy, manipulation, and corticosteroid injection. BMJ 1999, 318:1395-1396

79. Windt van der DA, Koes BW, Deville W, Boeke AJP, de Jong BA, Bouter LM: Effectiveness of corticosteroid injections versus physiotherapy for treatment of painful stiff shoulder in primary care: randomised trial. $B M J$ 1998, 317:1292-1296
80. Philadelphia Panel evidence-based clinical practice guidelines on selected rehabilitation interventions for shoulder pain. Phys Ther 2001, 81:1719-1730.

81. Vermeulen HM, Rozing PM, Obermann WR, le Cessie S, Vliet Vlieland TP: Comparison of high-grade and low-grade mobilization techniques in the management of adhesive capsulitis of the shoulder: randomized controlled trial. Phys Ther 2006, 86:355-368.

82. Dolder van den PA, Roberts DL: A trial into the effectiveness of soft tissue massage in the treatment of shoulder pain. Aust J Physiother 2003, 49:183-188.

83. Johnson AJ, Godges JJ, Zimmerman GJ, Ounanian LL: The effect of anterior versus posterior glide joint mobilization on external rotation range of motion in patients with shoulder adhesive capsulitis. J Orthop Sports Phys Ther 2007, 37:88-99.

84. Guler-Uysal F, Kozanoglu E: Comparison of the early response to two methods of rehabilitation in adhesive capsulitis. Swiss Med Wkly 2004, 134:353-358

85. Piligian G, Herbert R, Hearns M, Dropkin J, Landsbergis P, Cherniack M: Evaluation and management of chronic work-related musculoskeletal disorders of the distal upper extremity. Am J Ind Med 2000, 37:75-93.

86. Bisset L, Paungmali A, Vicenzino B, Beller E: A systematic review and metaanalysis of clinical trials on physical interventions for lateral epicondylalgia. Br J Sports Med 2005, 39:411-422.

87. McHardy A, Hoskins W, Pollard H, Onley R, Windsham R: Chiropractic treatment of upper extremity conditions: a systematic review. Manipulative Physiol Ther 2008, 31:146-159.

88. Smidt N, Assendelft WJ, Arola H, Malmivaara A, Greens S, Buchbinder R et al: Effectiveness of physiotherapy for lateral epicondylitis: a systematic review. Ann Med 2003, 35:51-62.

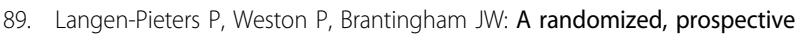
pilot study comparing chiropractic care and ultrasound for the treatment of lateral epicondylitis. Eur J Chiro 2003, 50:211-8.

90. Vicenzino $B$, Collins $D$, Wright $A$ : The initial effects of a cervical spine manipulative physiotherapy treatment on the pain and dysfunction of lateral epicondylalgia. Pain 1996, 68:69-74.

91. Paungmali A, O'Leary S, Souvlis T, Vicenzino B: Hypoalgesic and sympathoexcitatory effects of mobilization with movement for lateral epicondylalgia. Phys Ther 2003, 83:374-383.

92. Struijs PA, Damen PJ, Bakker EW, Blankevoort L, Assendelft WJ, van Dijk CN: Manipulation of the wrist for management of lateral epicondylitis: a randomized pilot study. Phys Ther 2003, 83:608-616.

93. Vicenzino B, Paungmali A, Buratowski S, Wright A: Specific manipulative therapy treatment for chronic lateral epicondylalgia produces uniquely characteristic hypoalgesia. Man Ther 2001, 6:205-212.

94. Smidt N, Windt van der DA, Assendelft WJ, Deville WL, Korthals-de Bos IB, Bouter LM: Corticosteroid injections, physiotherapy, or a wait-and-see policy for lateral epicondylitis: a randomised controlled trial. Lancet 2002, 359:657-662.

95. Drechsler WI, Knarr JF, Snyder-Mackler L: A comparison of two treatment regimens for lateral epicondylitis: a randomized trial of clinical interventions. J Sport Rehabil 1997, 6:226-234.

96. Dwars BJ, Feiter Pde, Patka P, Haarman H: Functional treatment of tennis elbow. Sports Medicine and Health 1990, 237-241.

97. Verhaar JA, Walenkamp $\mathrm{GH}$, van Mameren $\mathrm{H}$, Kester $\mathrm{AD}$, Linden van der $\mathrm{AJ}$ : Local corticosteroid injection versus Cyriax-type physiotherapy for tennis elbow. J Bone Joint Surg Br 1996, 78:128-132.

98. Bisset L, Beller E, Jull G, Brooks P, Darnell R, Vicenzino B: Mobilisation with movement and exercise, corticosteroid injection, or wait and see for tennis elbow: randomised trial. BMJ 2006, 333:939.

99. Nourbakhsh MR, Fearon FJ: The effect of oscillating-energy manual therapy on lateral epicondylitis: a randomized, placebo-control, doubleblinded study. J Hand Ther 2008, 21:4-13.

100. Bjordal JM, Lopes-Martins RA, Joensen J, Couppe C, Ljunggren AE, Stergioulas A, et al: A systematic review with procedural assessments and meta-analysis of low level laser therapy in lateral elbow tendinopathy (tennis elbow). BMC Musculoskelet Disord 2008, 9:75.

101. Trinh KV, Phillips SD, Ho E, Damsma K: Acupuncture for the alleviation of lateral epicondyle pain: a systematic review. Rheumatology (Oxford) 2004, 43:1085-1090. 
102. American Academy of Orthopaedic Surgeons: Clinical practic guidelines on the diagnosis of carpal tunnel syndrome. 2008.

103. O'Connor D, Marshall S, Massy-Westropp N: Non-surgical treatment (other than steroid injection) for carpal tunnel syndrome. Cochrane Database Syst Rev 2003, CD003219.

104. Goodyear-Smith F, Arroll B: What can family physicians offer patients with carpal tunnel syndrome other than surgery? A systematic review of nonsurgical management. Ann Fam Med 2004, 2:267-273.

105. Piazzini DB, Aprile I, Ferrara PE, Bertolini C, Tonali P, Maggi L, et al: A systematic review of conservative treatment of carpal tunnel syndrome. Clin Rehabil 2007, 21:299-314.

106. Davis PT, Hulbert JR, Kassak KM, Meyer JJ: Comparative efficacy of conservative medical and chiropractic treatments for carpal tunnel syndrome: a randomized clinical trial. J Manipulative Physiol Ther 1998, 21:317-326.

107. Tal-Akabi A, Rushton A: An investigation to compare the effectiveness of carpal bone mobilisation and neurodynamic mobilisation as methods of treatment for carpal tunnel syndrome. Man Ther 2000, 5:214-222.

108. Cibulka MT, White DM, Woehrle J, Harris-Hayes M, Enseki K, Fagerson TL, et al: Hip pain and mobility deficits-hip osteoarthritis: clinical practice guidelines linked to the international classification of functioning, disability, and health from the orthopaedic section of the American Physical Therapy Association. J Orthop Sports Phys Ther 2009, 39:A1-25.

109. Bussieres AE, Taylor JA, Peterson C: Diagnostic imaging practice guidelines for musculoskeletal complaints in adults-an evidence-based approach. Part 1. Lower extremity disorders. J Manipulative Physiol Ther 2007 30:684-717.

110. Brantingham JW, Globe G, Pollard H, Hicks M, Korporaal C, Hoskins W: Manipulative therapy for lower extremity conditions: expansion of literature review. J Manipulative Physiol Ther 2009, 32:53-71.

111. Hoeksma HL, Dekker J, Ronday HK, Heering A, van der LN, Vel C, et al: Comparison of manual therapy and exercise therapy in osteoarthritis of the hip: a randomized clinical trial. Arthritis Rheum 2004, 51:722-729.

112. National Institute for Health and Clinical Excellence: Osteoarthritis: National clinical guideline for care and management in adults. Clinical guideline 59 2008.

113. Licciardone JC, Stoll ST, Cardarelli KM, Gamber RG, Swift JN Jr, Winn WB: A randomized controlled trial of osteopathic manipulative treatment following knee or hip arthroplasty. J Am Osteopath Assoc 2004, 104:193-202

114. Hernandez-Molina G, Reichenbach S, Zhang B, Lavalley M, Felson DT: Effect of therapeutic exercise for hip osteoarthritis pain: results of a metaanalysis. Arthritis Rheum 2008, 59:1221-1228.

115. Deyle GD, Henderson NE, Matekel RL, Ryder MG, Garber MB, Allison SC: Effectiveness of manual physical therapy and exercise in osteoarthritis of the knee. A randomized, controlled trial. Ann Intern Med 2000, 132:173-181.

116. Deyle GD, Allison SC, Matekel RL, Ryder MG, Stang JM, Gohdes DD, et al: Physical therapy treatment effectiveness for osteoarthritis of the knee: a randomized comparison of supervised clinical exercise and manual therapy procedures versus a home exercise program. Phys Ther 2005, 85:1301-1317.

117. Crossley K, Bennell K, Green S, Cowan S, McConnell J: Physical therapy for patellofemoral pain: a randomized, double-blinded, placebo-controlled trial. Am J Sports Med 2002, 30:857-865.

118. Suter E, McMorland G, Herzog W, Bray R: Conservative lower back treatment reduces inhibition in knee-extensor muscles: a randomized controlled trial. J Manipulative Physiol Ther 2000, 23:76-80.

119. Bennell KL, Hinman RS, Metcalf BR, Buchbinder R, McConnell J, McColl G, et al: Efficacy of physiotherapy management of knee joint osteoarthritis: a randomised, double blind, placebo controlled trial. Ann Rheum Dis 2005, 64:906-912.

120. Moss P, Sluka K, Wright A: The initial effects of knee joint mobilization on osteoarthritic hyperalgesia. Man Ther 2007, 12:109-118.

121. Tucker M, Brantingham JW, Myburg C: The relative effectiveness of a nonsterodial anti-inflammatory medicaion (meloxicam) versus manipulation in the treatment of osteoarthritis of the knee. Eur J Chiro 2003, 50:163-84

122. Rowlands $B$, Brantingham JW: The efficacy of patella mobilisation in patients suffering from patellofemoral pain syndrome. J Neuromusculoskel System 1999, 7:9.
123. Stakes N, Myburgh C, Brantingham JW, Moyer R, Jensen M, Globe G: A prospective randomized clinical trial to determine efficacy of combined spinal manipulation and patella mobilization compared to patella mobilization alone in the conservative management of patellofemoral pain syndrome. J Am Chiro Assoc 2006, 43:11-8.

124. Taylor K, Brantingham JW: An investigation into the effect of exercise combined with patella mobilisation/manipulation in the treatment of patellofemoral pain syndrome. Eur J Chiro 2003, 51:17.

125. Pollard H, Ward G, Hoskins W, Hardy K: The effect of a manual therapy knee protocol on osteoarthritic knee pain: a randomised controlled trial. JCCA J Can Chiropr Assoc 2008, 52:229-242.

126. Perlman Al, Sabina A, Williams AL, Njike WY, Katz DL: Massage therapy for osteoarthritis of the knee: a randomized controlled trial. Arch Intern Med 2006, 166:2533-2538

127. Vavken $P$, Arrich F, Schuhfried O, Dorotka R: Effectiveness of pulsed electromagnetic field therapy in the management of osteoarthritis of the knee: a meta-analysis of randomized controlled trials. J Rehabil Med 2009, 41:406-411.

128. Hulme J, Robinson V, DeBie R, Wells G, Judd M, Tugwell P: Electromagnetic fields for the treatment of osteoarthritis. Cochrane Database Syst Rev 2002, CD003523.

129. White A, Foster NE', Cummings M, Barlas P: Acupuncture treatment for chronic knee pain: a systematic review. Rheumatology (Oxford) 2007, 46:384-390.

130. Fransen M, McConnell S: Exercise for osteoarthritis of the knee. Cochrane Database Syst Rev 2008, CD004376.

131. Bjordal JM, Johnson MI, Lopes-Martins RA, Bogen B, Chow R, Ljunggren AE: Short-term efficacy of physical interventions in osteoarthritic knee pain. A systematic review and meta-analysis of randomised placebocontrolled trials. BMC Musculoskelet Disord 2007, 8:51.

132. Wees van der PJ, Lenssen AF, Hendriks EJ, Stomp DJ, Dekker J, de Bie RA: Effectiveness of exercise therapy and manual mobilisation in ankle sprain and functional instability: a systematic review. Aust J Physiother 2006, 52:27-37.

133. Vicenzino $B$, Branjerdporn $M$, Teys $P$, Jordan $K$ : Initial changes in posterior talar glide and dorsiflexion of the ankle after mobilization with movement in individuals with recurrent ankle sprain. J Orthop Sports Phys Ther 2006, 36:464-471.

134. Eisenhart AW, Gaeta TJ, Yens DP: Osteopathic manipulative treatment in the emergency department for patients with acute ankle injuries. J Am Osteopath Assoc 2003, 103:417-421.

135. Green T, Refshauge K, Crosbie J, Adams R: A randomized controlled trial of a passive accessory joint mobilization on acute ankle inversion sprains. Phys Ther 2001, 81:984-994

136. Pellow JE, Brantingham JW: The efficacy of adjusting the ankle in the treatment of subacute and chronic grade I and grade II ankle inversion sprains. J Manipulative Physiol Ther 2001, 24:17-24.

137. Coetzer D, Brantingham JW, Nook B: The relative effectiveness of piroxicam compared to manipulation in the treatment of acute grades 1 and 2 inversion ankle sprains. J Neuromusculoskel System 2001, 9:9-12.

138. Collins N, P, Vicenzino B: The initial effects of a Mulligan's mobilization with movement technique on dorsiflexion and pain in subacute ankle sprains. Man Ther 2004, 9:77-82.

139. Lopez-Rodriguez S, Fernandez de-Las-Penas C, Alburquerque-Sendin F, Rodriguez-Blanco C, Palomeque-del-Cerro L: Immediate effects of manipulation of the talocrural joint on stabilometry and baropodometry in patients with ankle sprain. J Manipulative Physiol Ther 2007, 30:186-192.

140. Kohne E, Jones A, Korporaal C, Price JL, Brantingham JW, Globe G: A prospective, single-blinded, randomized, controlled clinical trial of the effects of manipulation on proprioception and ankle dorsiflexion in chronic recurrect ankle sprain. J Am Chiro Assoc 2007, 44:7-17.

141. Dimou E, Brantingham JW, Wood T: A randomized, controlled trial (with blinded observer) of chiropractic manipulation and Achilles stretching vs orthotics for the treatment of plantar fasciitis. J Am Chiro Assoc 2004, 41:32-42.

142. Govender N, Kretzmann H, Price J, Brantingham JW, Globe G: A singleblinded randomized placebo-controlled clinical trial of manipulation and mobilization in the treatment of Morton's neuroma. J Am Chiro AssoC 2007, 44:9-18 
143. Shamus J, Shamus E, Gugel RN, Brucker BS, Skaruppa C: The effect of sesamoid mobilization, flexor hallucis strengthening, and gait training on reducing pain and restoring function in individuals with hallux limitus: a clinical trial. J Orthop Sports Phys Ther 2004, 34:368-376.

144. Brantingham JW, Guiry S, Kretzmann H, Globe G, Kite V: A pilot study of the efficacy of a conservative chiropractic protocol using graded mobilization and ice in the treatment of sympomatic hallux abductogalvus bunions. Clin Chiro 2005, 8:117-33.

145. Brooks SC, Potter BT, Rainey JB: Treatment for partial tears of the lateral ligament of the ankle: a prospective trial. Br Med J (Clin Res Ed) 1981, 282:606-607.

146. Wynne MM, Burns JM, Eland DC, Conatser RR, Howell JN: Effect of counterstrain on stretch reflexes, hoffmann reflexes, and clinical outcomes in subjects with plantar fasciitis. J Am Osteopath Assoc 2006, 106:547-556.

147. Cleland JA, Abbott JH, Kidd MO, Stockwell S, Cheney S, Gerrard DF, et al: Manual physical therapy and exercise versus electrophysical agents and exercise in the management of plantar heel pain: a multicenter randomized clinical trial. J Orthop Sports Phys Ther 2009, 39:573-585.

148. Lin CW, Moseley AM, Haas M, Refshauge KM, Herbert RD: Manual therapy in addition to physiotherapy does not improve clinical or economic outcomes after ankle fracture. J Rehabil Med 2008, 40:433-439.

149. McPoil TG, Martin RL, Cornwall MW, Wukich DK, Irrgang JJ, Godges JJ: Heel pain-plantar fasciitis: clinical practice guildelines linked to the international classification of function, disability, and health from the orthopaedic section of the American Physical Therapy Association. J Orthop Sports Phys Ther 2008, 38:A1-A18.

150. Handoll HH, Rowe BH, Quinn KM, de Bie R: Interventions for preventing ankle ligament injuries. Cochrane Database Syst Rev 2001, CD000018.

151. McNeill C: Epidemiology. Temporomandibular Disorders: Guidelines For Classification, Assessment, and Management Quintessence Publishing Co, Inc 1993, 19-22

152. Dworkin SF, Huggins KH, Wilson L, Mancl L, Turner J, Massoth D, et al: A randomized clinical trial using research diagnostic criteria for temporomandibular disorders-axis II to target clinic cases for a tailored self-care TMD treatment program. J Orofac Pain 2002, 16:48-63.

153. McNeely ML, Armijo OS, Magee DJ: A systematic review of the effectiveness of physical therapy interventions for temporomandibular disorders. Phys Ther 2006, 86:710-725

154. Medlicott MS, Harris SR: A systematic review of the effectiveness of exercise, manual therapy, electrotherapy, relaxation training, and biofeedback in the management of temporomandibular disorder. Phys Ther 2006, 86:955-973.

155. Taylor M, Suvinen T, Reade P: The effect of grade IV distraction mobilization on patients with temporomandibular pain-dysfunction disorder. Physiotherapy Theory and Practice 1994, 10:129-136.

156. Carmeli E, Sheklow SL, Blommenfeld I: Comparitive study of repositioning splint therapy and passive manual range of motion techniques for anterior displaced temporomandibular discs with unstable excursive reduction. Physiotherapy 2001, 87:26-36

157. De Laat A, Stappaerts K, Papy S: Counseling and physical therapy as treatment for myofascial pain of the masticatory system. J Orofac Pain 2003, 17:42-49.

158. Monaco A, Cozzolino V, Cattaneo R, Cutilli T, Spadaro A: Osteopathic manipulative treatment (OMT) effects on mandibular kinetics: kinesiographic study. Eur J Paediatr Dent 2008, 9:37-42.

159. Ismail F, Demling A, Hessling K, Fink M, Stiesch-Scholz M: Short-term efficacy of physical therapy compared to splint therapy in treatment of arthrogenous TMD. J Oral Rehabil 2007, 34:807-813.

160. Carville SF, Arendt-Nielsen S, Bliddal H, Blotman F, Branco JC, Buskila D, et al: EULAR evidence-based recommendations for the management of fibromyalgia syndrome. Ann Rheum Dis 2008, 67:536-541.

161. Wolfe F, Smythe HA, Yunus MB, Bennett RM, Bombardier C, Goldenberg DL, et al: The American College of Rheumatology 1990 Criteria for the Classification of Fibromyalgia. Report of the Multicenter Criteria Committee. Arthritis Rheum 1990, 33:160-172.

162. Schneider M, Vernon $H, K_{0}$ G, Lawson G, Perera J: Chiropractic management of fibromyalgia syndrome: a systematic review of the literature. J Manipulative Physiol Ther 2009, 32:25-40.

163. Ernst E: Chiropractic treatment for fibromyalgia: a systematic review. Clin Rheumatol 2009, 28:1175-1178.
164. Goldenberg DL, Burckhardt C, Crofford L: Management of fibromyalgia syndrome. JAMA 2004, 292:2388-2395.

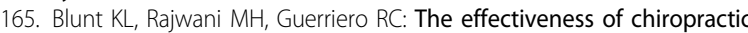
management of fibromyalgia patients: a pilot study. J Manipulative Physiol Ther 1997, 20:389-399.

166. Tyers S, Smith RB: A comparison of cranial electrotherapy stimulation alone or with chiropractic therapies in the treatment of fibromyalgia. Am Chiropractor 2001, 23:39-41.

167. Wise P, Walsh M, Littlejohn G: Efficacy of chiropractic treatment on fibromyalgia syndrome; a randomized controlled trial. Eur J Chiro 2002, 102:321-5.

168. Panton LB, Figueroa A, Kingsley JD, Hornbuckle L, Wilson J, St John N, et al: Effects of resistance training and chiropractic treatment in women with fibromyalgia. J Altern Complement Med 2009, 15:321-328.

169. Gamber RG, Shores JH, Russo DP, Jimenez C, Rubin BR: Osteopathic manipulative treatment in conjunction with medication relieves pain associated with fibromyalgia syndrome: results of a randomized clinical pilot project. J Am Osteopath Assoc 2002, 102:321-325.

170. Brattberg $\mathrm{G}$ : Connective tissue massage in the treatment of fibromyalgia. Eur J Pain 1999, 3:235-244.

171. Richards KC, Gibson R, Overton-McCoy AL: Effects of massage in acute and critical care. AACN Clin Issues 2000, 11:77-96.

172. Ekici G, Bakar Y, Akbayrak T, Yuksel I: Comparison of manual lymph drainage therapy and connective tissue massage in women with fibromyalgia: a randomized controlled trial. J Manipulative Physiol Ther 2009, 32:127-133.

173. Busch AJ, Barber KA, Overend TJ, Peloso PM, Schachter CL: Exercise for treating fibromyalgia syndrome. Cochrane Database Syst Rev 2007, CD003786.

174. Vernon $\mathrm{H}$, Schneider M: Chiropractic management of myofascial trigger points and myofascial pain syndrome: a systematic review of the literature. J Manipulative Physiol Ther 2009, 32:14-24.

175. Gam AN, Warming S, Larsen LH, Jensen B, Hoydalsmo O, Allon I, et al: Treatment of myofascial trigger-points with ultrasound combined with massage and exercise-a randomised controlled trial. Pain 1998, 77:73-79.

176. Dardzinski JA, Ostrov BE, Hamann LS: Myofascial pain unresponsive to standard treatment: successful use of a strain and counterstrain technique with physical therapy. J Clin Rheumatol 2000, 6:169-174.

177. Greene C, Debias D, Helig D, Nicholas A, England K, Ehrenfeuchter W, et al: The effect of helium-neon laser and osteopathic manipulation on softtissue trigger points. J Am Osteopath Assoc 1990, 90:638-639.

178. Hanten WP, Olson SL, Butts NL, Nowicki AL: Effectiveness of a home program of ischemic pressure followed by sustained stretch for treatment of myofascial trigger points. Phys Ther 2000, 80:997-1003.

179. Jaeger $B$, Reeves $J$ L: Quantification of changes in myofascial trigger point sensitivity with the pressure algometer following passive stretch. Pain 1986, 27:203-210.

180. Hong CZ, Chen YC, Pon CH, Yu J: Immediate effects of various physical medicine modalities on pain threshold of an active myofascial trigger point. j musculoskel pain 1993, 1:37-53.

181. Hou CR, Tsai LC, Cheng KF, Chung KC, Hong CZ: Immediate effects of various physical therapeutic modalities on cervical myofascial pain and trigger-point sensitivity. Arch Phys Med Rehabil 2002, 83:1406-1414.

182. Hanten WP, Barret M, Gillespie-Plesko M, Jump KA, Olson SL: Effects of active head retraction with retraction/extension and occipital release on the pressure pain threshold of cervical and scapular trigger points. Physiother Theory Pract 1997, 13:285-291.

183. Fernandez-de-las-Penas C, Alonso-Blanco C, Fernandez-Carnero J, Miangolarra-Page JC: The immediate effects of ischemic compression technique and transverse friction massage on tenderness of active and latent myofascial trigger points: a pilot study. J Bodywork Mov Ther 2009, 10:3-9.

184. Terrett AC, Vernon $\mathrm{H}$ : Manipulation and pain tolerance. A controlled study of the effect of spinal manipulation on paraspinal cutaneous pain tolerance levels. Am J Phys Med 1984, 63:217-225.

185. Vernon HT, Aker P, Burns S, Viljakaanen S, Short L: Pressure pain threshold evaluation of the effect of spinal manipulation in the treatment of chronic neck pain: a pilot study. J Manipulative Physio/ Ther 1990, 13:13-16.

186. Cote $\mathrm{P}, \mathrm{Mior}$ SA, Vernon H: The short-term effect of a spinal manipulation on pain/pressure threshold in patients with chronic mechanical low back pain. J Manipulative Physiol Ther 1994, 17:364-368. 
187. Atienza-Meseguer A, Fernandez-de-las-Penas C, Navarro-Poza JL, RodriguezBlanco C, Bosca-Gandia JJ: Immediate effects of the strain/counterstrain technique in local pain evoked by tender points in the upper trapezius muscle. Clin Chiro 2006, 9:112-118.

188. Fryer G, Hodgson L: The effect of manual pressure release on myofascial trigger points in the upper trapezius muscle. J Bodywork Mov Ther 2005, 9:248-255.

189. The International Classification of Headache Disorders. Cephalalgia , 2 2004, 24(Suppl 1):9-160.

190. Scotish Intercollegiate Guideline Network: Diagnosis and management of headache in adults. 2008, 107.

191. Astin JA, Ernst E: The effectiveness of spinal manipulation for the treatment of headache disorders: a systematic review of randomized clinical trials. Cephalalgia 2002, 22:617-623.

192. Bronfort G, Nilsson N, Haas M, Evans R, Goldsmith CH, Assendelft WJ, et al: Non-invasive physical treatments for chronic/recurrent headache. Cochrane Database Syst Rev 2004, CD001878.

193. Parker GB, Pryor DS, Tupling H: Why does migraine improve during a clinical trial? Further results from a trial of cervical manipulation for migraine. Aust N Z J Med 1980, 10:192-198.

194. Tuchin PJ, Pollard H, Bonello R: A randomized controlled trial of chiropractic spinal manipulative therapy for migraine. J Manipulative Physiol Ther 2000, 23:91-95.

195. Nelson CF, Bronfort G, Evans R, Boline P, Goldsmith C, Anderson AV: The efficacy of spinal manipulation, amitriptyline and the combination of both therapies for the prophylaxis of migraine headaches. J Manipulative Physiol Ther 1998, 21:511-519.

196. Lawler SP, Cameron LD: A randomized, controlled trial of massage therapy as a treatment for migraine. Ann Behav Med 2006, 32:50-59.

197. Linde K, Allais G, Brinkhaus B, Manheimer E, Vickers A, White AR: Acupuncture for migraine prophylaxis. Cochrane Database Syst Rev 2009, CD001218.

198. Nestoriuc Y, Martin A, Rief W, Andrasik F: Biofeedback treatment for headache disorders: a comprehensive efficacy review. Appl Psychophysiol Biofeedback 2008, 33:125-140.

199. McCrory DC, Penzien DB, Hasselblad V, Gray RN: Evidence Report: Behavioral and Physical Treatments for Tension-type and Cervicogenic Headache. FCER Research 2001.

200. Lenssinck ML, Damen L, Verhagen AP, Berger MY, Passchier J, Koes BW: The effectiveness of physiotherapy and manipulation in patients with tension-type headache: a systematic review. Pain 2004, 112:381-388.

201. Fernandez-de-las-Penas C, Alonso-Blanco C, Cuadrado ML, Miangolarra JC, Barriga FJ, Pareja JA: Are manual therapies effective in reducing pain from tension-type headache?: a systematic review. Clin J Pain 2006, 22:278-285.

202. Boline PD, Kassak K, Bronfort G, Nelson C, Anderson AV: Spinal manipulation vs. amitriptyline for the treatment of chronic tension-type headaches: a randomized clinical trial. J Manipulative Physiol Ther 1995, 18:148-154.

203. Bove G, Nilsson N: Spinal manipulation in the treatment of episodic tension-type headache: a randomized controlled trial. JAMA 1998, 280:1576-1579.

204. Hanten WP, Olson SL, hodson JL, imler VL, knab VM, Magee JL: The Effectiveness of CV-4 and Resting Position Techniques on Subjects with Tension-Type Headaches. The Journal of Manual \& Manipulative Therapy 1999, 7:64-70.

205. Demirturk F, Akarcali I, Akbayrak R, Citak I, Inan L: Results of two different manual therapy techniques in chronic tension-type headache. The Pain Clinic 2002, 14:121-128

206. Donkin RD, Parkin-Smith GF, Gomes AN: Possible effect of chiropractic manipulation and combined manual traction and manipulation on tension-type headache: a pilot study. Journal of the Neuromusculoskeletal System 2002, 10:89-97.

207. Ahonen E, Hakumaki M, Mahlamaki S, Partanen J, Riekkinen P, Sivenius J: Effectiveness of acupuncture and physiotherapy on myogenic headache a comparative study. Acupunct Electrother Res 1984, 9:141-150.

208. Carlsson J, Fahlcrantz A, Augustinsson LE: Muscle tenderness in tension headache treated with acupuncture or physiotherapy. Cephalalgia 1990, 10:131-141.

209. Wylie KR, Jackson C, Crawford PM: Does psychological testing help to predict the response to acupuncture or massage/relaxation therapy in patients presenting to a general neurology clinic with headache?. Tradit Chin Med 1997, 17:130-139.

210. Hoyt WH, Shaffer F, Bard DA, Benesler JS, Blankenhorn GD, Gray JH, et al: Osteopathic manipulation in the treatment of muscle-contraction headache. JAOA 1979, 78:322-325.

211. Jay GW, Brunson J, Branson SJ: The effectiveness of physical therapy in the treatment of chronic daily headaches. Headache 1989, 29:156-162.

212. Marcus DA, Scharff L, Turk DC: Nonpharmacological management of headaches during pregnancy. Psychosom Med 1995, 57:527-535.

213. Anderson RE, Seniscal C: A comparison of selected osteopathic treatment and relaxation for tension-type headaches. Headache 2006, 46:1273-1280.

214. Linde $K$, Allais G, Brinkhaus B, Manheimer E, Vickers A, White AR: Acupuncture for tension-type headache. Cochrane Database Syst Rev 2009, CD007587.

215. Sjaastad O, Fredriksen TA, Pfaffenrath V: Cervicogenic headache: diagnostic criteria. Headache 1998, 38:442-445

216. Fernandez-de-las-Penas C, Alonso-Blanco C, Cuadrado ML, Pareja JA: Spinal manipulative therapy in the management of cervicogenic headache. Headache 2005, 45:1260-1263.

217. Bitterli J, Graf R, Robert F, Adler R, Mumenthaler M: Zur Objektivierung der manualtherapeutischen BeeinfluBbarkeit des spondylogenen Kopfschmerzes [Objective criteria for the evaluation of chiropractic treatment of spondylotic headache]. Nervenarzt 1977, 48:259-262.

218. Howe DH, Newcombe RG, Wade MT: Manipulation of the cervical spine a pilot study. J $R$ Coll Gen Pract 1983, 33:574-579.

219. Ammer K, Hein L, Rathkolb O: [Physical therapy in occipital headaches]. Manuelle Med 1990, 28:65-68.

220. Jull G, Trott P, Potter H, Zito G, Niere K, Shirley D, et al: A randomized controlled trial of exercise and manipulative therapy for cervicogenic headache. Spine 2002, 27:1835-1843.

221. Nilsson N, Christensen HW, Hartvigsen J: The effect of spinal manipulation in the treatment of cervicogenic headache. $J$ Manipulative Physiol Ther 1997, 20:326-330.

222. Whittingham W: The efficacy of cervical adjustments (Toggle recoil) for chronic cervicogenic headaches [thesis] Melbourne, Australia: Royal Melbourne Institute of Technology; 1999.

223. Hall T, Chan HT, Christensen L, Odenthal B, Wells C, Robinson K: Efficacy of a C1-C2 self-sustained natural apophyseal glide (SNAG) in the management of cervicogenic headache. J Orthop Sports Phys Ther 2007, 37:100-107.

224. Jensen OK, Nielsen FF, Vosmar L: An open study comparing manual therapy with the use of cold packs in the treatment of post-traumatic headache. Cephalalgia 1990, 10:241-250.

225. National Heart LaBI: US Guidelines on the Management of Asthma. Expert Panel Report 3 2007, 3.

226. Scottish Intercollegiate Guidelines Network: British Guideline on the Management of Asthma. The British Thoracic Society 2009, 1-132.

227. Ernst E: Spinal manipulation for asthma: A systematic review of randomised clinical trials. Respir Med 2009, 103:1791-1795.

228. Hondras MA, Linde K, Jones AP: Manual therapy for asthma. Cochrane Database Syst Rev 2001, CD001002.

229. Balon JW, Mior SA: Chiropractic care in asthma and allergy. Ann Allergy Asthma Immunol 2004, 93:S55-S60.

230. Hawk C, Khorsan R, Lisi AJ, Ferrance RJ, Evans MW: Chiropractic care for nonmusculoskeletal conditions: a systematic review with implications for whole systems research. J Altern Complement Med 2007, 13:491-512.

231. Nielsen NH, Bronfort G, Bendix T, Madsen F, Weeke B: Chronic asthma and chiropractic spinal manipulation: a randomized clinical trial. Clin Exp Allergy 1995, 25:80-88.

232. Balon J, Aker PD, Crowther ER, Danielson C, Cox PG, O'Shaughnessy D, et al: A comparison of active and simulated chiropractic manipulation as adjunctive treatment for childhood asthma. N Engl J Med 1998, 339:1013-1020.

233. Guiney PA, Chou R, Vianna A, Lovenheim J: Effects of osteopathic manipulative treatment on pediatric patients with asthma: a randomized controlled trial. J Am Osteopath Assoc 2005, 105:7-12.

234. Field T, Henteleff T, Hernandez-Reif M, Martinez E, Mavunda K, Kuhn C, et al: Children with asthma have improved pulmonary functions after massage therapy. J Pediatr 1998, 132:854-858.

235. Brygge T, Heinig JH, Collins P, Ronborg S, Gehrchen PM, Hilden J, et al: Reflexology and bronchial asthma. Respir Med 2001, 95:173-179. 
236. BTS Guidelines for the Management of Community Acquired Pneumonia in Adults. Thorax 2001, 56(Suppl 4):IV1-64.

237. Mandell LA, Wunderink RG, Anzueto A, Bartlett JG, Campbell GD, Dean NC, et al: Infectious Diseases Society of America/American Thoracic Society consensus guidelines on the management of community-acquired pneumonia in adults. Clin Infect Dis 2007, 44(Suppl 2):S27-S72.

238. Noll DR, Shores JH, Gamber RG, Herron KM, Swift J Jr: Benefits of osteopathic manipulative treatment for hospitalized elderly patients with pneumonia. J Am Osteopath Assoc 2000, 100:776-782

239. Bhattacharyya N, Baugh RF, Orvidas L, Barrs D, Bronston LJ, Cass S, et al: Clinical practice guideline: benign paroxysmal positional vertigo. Otolaryngol Head Neck Surg 2008, 139:S47-S81.

240. Reid SA, Rivett DA: Manual therapy treatment of cervicogenic dizziness: a systematic review. Man Ther 2005, 10:4-13.

241. Karlberg M, Magnusson M, Malmstrom EM, Melander A, Moritz U: Postural and symptomatic improvement after physiotherapy in patients with dizziness of suspected cervical origin. Arch Phys Med Rehabil 1996, 77:874-882.

242. Reid SA, Rivett DA, Katekar MG, Callister R: Sustained natural apophyseal glides (SNAGs) are an effective treatment for cervicogenic dizziness. Man Ther 2008, 13:357-366.

243. Hillier SL, Hollohan V: Vestibular rehabilitation for unilateral peripheral vestibular dysfunction. Cochrane Database Syst Rev 2007, CD005397.

244. Wessel MA, Cobb JC, Jackson EB, Harris GS, Detwiler AC: Paroxysmal fussing in infancy, sometimes called "colic". Pediatrics 1954, 14:421-434

245. Husereau D, Clifford T, Aker P: Spinal manipulation for infantile colic. Canadian Coordinating office for Health Technology Assessment. Ottawa 2003, 42.

246. Brand $P$, Engelbert $R$, Helders $P$ : Systematic review of effects of manual therapy in infants with kinetic imbalance due to suboccipital strain (KISS) syndrome. J Man \& Manip Ther 2005, 13:209-214.

247. Ernst E: Chiropractic manipulation for non-spinal pain-a systematic review. N Z Med J 2003, 116:U539.

248. Gotlib A, Rupert R: Chiropractic manipulation in pediatric health conditions - an updated systematic review. Chiropr Osteopat 2008, 16:11.

249. Ernst E: Chiropractic spinal manipulation for infant colic: a systematic review of randomised clinical trials. Int J Clin Pract 2009, 63:1351-1353.

250. Koonin S, Karpelowsky AS, Yelverton CJ: A comparative study to determine the efficacy of chiropractic spinal manipulative therapy and allopathic medication inthe treatment of infantile colic. WFC 7th Biennial Congress Proceedings; Orlando. May 1-3, 2003 330-1.

251. Mercer C, Nook B: The efficacy of chiropractic spinal adjustments as a treatment protocol in the management of infant colic. World Federation of Chiropractic. 5th Biennial Congress, 17-22 May 1999 Haldman S, Murphy B $170-1$.

252. Wiberg JM, Nordsteen J, Nilsson N: The short-term effect of spinal manipulation in the treatment of infantile colic: a randomized controlled clinical trial with a blinded observer. J Manipulative Physiol Ther 1999, 22:517-522.

253. Browning M: Comparison of the short-term effects of chiropractic spinal manipulation and occipito-sacral decompression in the treatment of infant colic: a single-blinded, randomised, comparison trial. Clinical Chiropractic 2009, 11:122-129.

254. Olafsdottir E, Forshei S, Fluge G, Markestad T: Randomised controlled trial of infantile colic treated with chiropractic spinal manipulation. Arch Dis Child 2001, 84:138-141.

255. Hayden C, Mullinger B: A preliminary assessment of the impact of cranial osteopathy for the relief of infantile colic. Complement Ther Clin Pract 2006, 12:83-90.

256. Huhtala V, Lehtonen L, Heinonen R, Korvenranta H: Infant massage compared with crib vibrator in the treatment of colicky infants. Pediatrics 2000, 105:E84

257. Arikan D, Alp H, Gozum S, Orbak Z, Cifci EK: Effectiveness of massage, sucrose solution, herbal tea or hydrolysed formula in the treatment of infantile colic. J Clin Nurs 2008, 17:1754-1761.

258. Lucassen PL, Assendelft WJ, Gubbels JW, van Eijk JT, van Geldrop WJ, Neven AK: Effectiveness of treatments for infantile colic: systematic review. BMJ 1998, 316:1563-1569.

259. Garrison MM, Christakis DA: A systematic review of treatments for infant colic. Pediatrics 2000, 106:184-190.
260. World Health Organization: The ICD-10 classification of mental and behavioural disorders: Clinical descriptions and diagnostic guidelines. 1992.

261. Fritz G, Rockney R, Bernet W, Arnold V, Beitchman J, Benson RS, et al: Practice parameter for the assessment and treatment of children and adolescents with enuresis. J Am Acad Child Adolesc Psychiatry 2004 43:1540-1550.

262. Glazener CM, Evans JH, Cheuk DK: Complementary and miscellaneous interventions for nocturnal enuresis in children. Cochrane Database Syst Rev 2005, CD005230.

263. Reed WR, Beavers S, Reddy SK, Kern G: Chiropractic management of primary nocturnal enuresis. J Manipulative Physiol Ther 1994, 17:596-600.

264. Leboeuf C, Brown P, Herman A, Leembruggen K, Walton D, Crisp TC: Chiropractic care of children with nocturnal enuresis: a prospective outcome study. J Manipulative Physiol Ther 1991, 14:110-115.

265. Pediatric Society of New Zealand: Best practice evidence based guideline: Nocturnal enuresis. 2005.

266. Scottish Intercollegiate Guidelines Network: Diagnosis and management of childhood otitis media in primary care. 2003, 66.

267. Mills MV, Henley CE, Barnes LL, Carreiro JE, Degenhardt BF: The use of osteopathic manipulative treatment as adjuvant therapy in children with recurrent acute otitis media. Arch Pediatr Adolesc Med 2003, 157:861-866.

268. Subcommittee on Management of Acute Otitis Media: Diagnosis and management of acute otitis media. Pediatics 2004, 113:1451-1465.

269. Wahl RA, Aldous MB, Worden KA, Grant KL: Echinacea purpurea and osteopathic manipulative treatment in children with recurrent otitis media: a randomized controlled trial. BMC Complement Altern Med 2008, 8:56.

270. Chobanian AV, Bakris GL, Black HR, Cushman WC, Green LA, Izzo JL Jr, et al: The Seventh Report of the Joint National Committee on Prevention, Detection, Evaluation, and Treatment of High Blood Pressure: the JNC 7 report. JAMA 2003, 289:2560-2572.

271. National Institute for Health and Clinical Excellence: Hypertension: management of hypertension in adults in primary care. Clinical Care Guideline 2006, 34.

272. Goertz CH, Grimm RH, Svendsen K, Grandits G: Treatment of Hypertension with Alternative Therapies (THAT) Study: a randomized clinical trial. J Hypertens 2002, 20:2063-2068.

273. Yates $R G$, Lamping DL, Abram NL, Wright C: Effects of chiropractic treatment on blood pressure and anxiety: a randomized, controlled trial. J Manipulative Physiol Ther 1988, 11:484-488.

274. Bakris G, Dickholtz M Sr, Meyer PM, Kravitz G, Avery E, Miller M, et al: Atlas vertebra realignment and achievement of arterial pressure goal in hypertensive patients: a pilot study. J Hum Hypertens 2007, 21:347-352.

275. Lefebvre G, Pinsonneault O, Antao V, Black A, Burnett M, Feldman K, et al: Primary dysmenorrhea consensus guideline. J Obstet Gynaecol Can 2005, 27:1117-1146.

276. Proctor ML, Hing W, Johnson TC, Murphy PA: Spinal manipulation for primary and secondary dysmenorrhoea. Cochrane Database Syst Rev 2006, 3:CD002119.

277. Boesler D, Warner M, Alpers A, Finnerty EP, Kilmore MA: Efficacy of highvelocity low-amplitude manipulative technique in subjects with lowback pain during menstrual cramping. J Am Osteopath Assoc 1993, 93:203-204.

278. Snyder BJ, Sanders GE: Evaluation of the Toftness system of chiropractic adjusting for subjects with chronic back pain, chronic tension headaches, or primary dysmenorrhea. Chiro Tech 1996, 8:3-9.

279. Kokjohn K, Schmid DM, Triano JJ, Brennan PC: The effect of spinal manipulation on pain and prostaglandin levels in women with primary dysmenorrhea. J Manipulative Physiol Ther 1992, 15:279-285.

280. Tomason PR, Fisher BL, Carpenter PA: Effectiveness of spinal manipulative therapy in treatment of primary dysmenorrhea: A pilot study. J of Man and Phys Therapeutics 1979, 2:140-145.

281. Hondras MA, Long CR, Brennan PC: Spinal manipulative therapy versus a low force mimic maneuver for women with primary dysmenorrhea: a randomized, observer-blinded, clinical trial. Pain 1999, 81:105-114.

282. Royal College of Obstetricians and Gynaecologists: Management of premenstual syndrome. Green-top Guideline 2007, 48.

283. Halbreich U, Backstrom T, Eriksson E, O'brien S, Calil H, Ceskova E, et al: Clinical diagnostic criteria for premenstrual syndrome and guidelines for 
their quantification for research studies. Gynecol Endocrinol 2007, 23:123-130.

284. Stevinson C, Ernst E: Complementary/alternative therapies for premenstrual syndrome: a systematic review of randomized controlled trials. Am J Obstet Gynecol 2001, 185:227-235.

285. Fugh-Berman A, Kronenberg F: Complementary and alternative medicine (CAM) in reproductive-age women: a review of randomized controlled trials. Reprod Toxicol 2003, 17:137-152

286. Walsh MJ, Polus BI: A randomized, placebo-controlled clinical trial on the efficacy of chiropractic therapy on premenstrual syndrome. $J$ Manipulative Physiol Ther 1999, 22:582-585.

287. Hernandez-Reif M, Martinez A, Field T, Quintero O, Hart S, Burman I: Premenstrual symptoms are relieved by massage therapy. J Psychosom Obstet Gynaecol 2000, 21:9-15.

288. Oleson T, Flocco W: Randomized controlled study of premenstrual symptoms treated with ear, hand, and foot reflexology. Obstet Gynecol 1993, 82:906-911.

289. Reventlow SD, Hvas L, Malterud K: Making the invisible body visible. Bone scans, osteoporosis and women's bodily experiences. Soc Sci Med 2006, 62:2720-2731.

290. Barnett AG, Pols van der JC, Dobson AJ: Regression to the mean: what it is and how to deal with it. Int J Epidemiol 2005, 34:215-220.

291. Kaptchuk TJ: The placebo effect in alternative medicine: can the performance of a healing ritual have clinical significance?. Ann Intern Med 2002, 136:817-825.

292. Sox HC Jr, Margulies I, Sox CH: Psychologically mediated effects of diagnostic tests. Ann Intern Med 1981, 95:680-685.

293. Kaptchuk TJ: Powerful placebo: the dark side of the randomised controlled trial. The Lancet 1998, 351:1722-1725.

294. Kelley JM, Lembo AJ, Ablon JS, Villanueva JJ, Conboy LA, Levy R, et al: Patient and Practitioner Influences on the Placebo Effect in Irritable Bowel Syndrome. Psychosom Med 2009, 71:789-797.

295. Kaptchuk TJ, Stason WB, Davis RB, Legedza AR, Schnyer RN, Kerr CE, et al: Sham device $v$ inert pill: randomised controlled trial of two placebo treatments. BMJ 2006, 332:391-397.

296. Oths K. Communication in a chiropractic clinic: how a D.C. treats his patients. Cult Med Psychiatry 1994, 18:83-113.

297. Adler HM, Hammett VB: The doctor-patient relationship revisited. An analysis of the placebo effect. Ann Intern Med 1973, 78:595-598.

298. Novack DH: Therapeutic aspects of the clinical encounter. J Gen Intern Med 1987, 2:346-355.

299. De Vries $R$, Lemmens $T$ : The social and cultural shaping of medical evidence: case studies from pharmaceutical research and obstetric science. Soc Sci Med 2006, 62:2694-2706.

300. Verhoef MJ, Lewith G, Ritenbaugh C, Boon H, Fleishman S, Leis A: Complementary and alternative medicine whole systems research: beyond identification of inadequacies of the RCT. Complement Ther Med 2005, 13:206-212.

301. Antman K, Lagakos S, Drazen J: Designing and funding clinical trials of novel therapies. N Engl J Med 2001, 344:762-763.

302. Hoffer L: Proof versus plausibility: rules of engagement for the struggle to evaluate alternative cancer therapies. CMAJ 2001, 164:351-353.

303. Khalsa PS, Eberhart A, Cotler A, Nahin R: The 2005 conference on the biology of manual therapies. J Manipulative Physiol Ther 2006, 29:341-346.

304. Rubinstein SM: Adverse events following chiropractic care for subjects with neck or low-back pain: do the benefits outweigh the risks?. J Manipulative Physiol Ther 2008, 31:461-464.

305. Ernst E: Adverse effects of spinal manipulation: a systematic review. $J R$ Soc Med 2007, 100:330-338.

306. Rubinstein SM, Peerdeman SM, van Tulder MW, Riphagen I, Haldeman S: A systematic review of the risk factors for cervical artery dissection. Stroke 2005, 36:1575-1580.

307. Michaeli A: A reported occurrence and nature of complications following manipulative physiotherapy in South Afrika. Aust Physiother 1993, 39:309-315.

308. Haldeman S, Carey P, Townsend M, Papadopoulos C: Arterial dissections following cervical manipulation: the chiropractic experience. CMAJ 2001, 165:905-906.

309. Cassidy JD, Boyle E, Cote P, He Y, Hogg-Johnson S, Silver F, et al: Risk of vertebrobasilar stroke and chiropractic care: results of a populationbased case-control and case-crossover study. Spine 2008, 33:S176-S183.
310. Hurwitz EL, Morgenstern H, Vassilaki M, Chiang LM: Adverse reactions to chiropractic treatment and their effects on satisfaction and clinical outcomes among patients enrolled in the UCLA Neck Pain Study. $J$ Manipulative Physiol Ther 2004, 27:16-25.

311. Hurwitz EL, Morgenstern H, Vassilaki M, Chiang LM: Frequency and clinical predictors of adverse reactions to chiropractic care in the UCLA neck pain study. Spine 2005, 30:1477-1484.

312. Assendelft WJ, Bouter LM, Knipschild PG: Complications of spinal manipulation: a comprehensive review of the literature. J Fam Pract 1996, 42:475-480.

313. Institute for Clinical Systems Improvement: ICSI Health Care Guidelines: Assessment and management of chronic pain. Institute for Clinical Systems Improvement 2005, 1-77.

314. Haldeman S, Rubinstein SM: Cauda equina syndrome in patients undergoing manipulation of the lumbar spine. Spine 1992, 17:1469-1473.

315. Vohra S, Johnston BC, Cramer K, Humphreys K: Adverse events associated with pediatric spinal manipulation: a systematic review. Pediatrics 2007, 119:e275-e283.

316. Stevinson C, Honan W, Cooke B, Ernst E: Neurological complications of cervical spine manipulation. $J$ R Soc Med 2001, 94:107-110.

317. Nissen SE: ADHD drugs and cardiovascular risk. N Engl J Med 2006 354:1445-1448

318. Adams D, Amernic $H$, Humphreys K: A survey of complementary and alternative medicine practitioners' knowledge, attitudes, and behavior regarding children in their practice. San Francisco, CA206.

319. Moher D, Pham B, Lawson ML, Klassen TP: The inclusion of reports of randomised trials published in languages other than English in systematic reviews. Health Technol Assess 2003, 7:1-90.

320. Juni P, Holenstein F, Sterne J, Bartlett C, Egger M: Direction and impact of language bias in meta-analyses of controlled trials: empirical study. Int J Epidemiol 2002, 31:115-123.

321. Galandi D, Schwarzer G, Antes G: The demise of the randomised controlled trial: bibliometric study of the German-language health care literature, 1948 to 2004. BMC Med Res Methodol 2006, 6:30.

322. Moher D, Tetzlaff J, Tricco AC, Sampson M, Altman DG: Epidemiology and reporting characteristics of systematic reviews. PLoS Med 2007, 4:e78.

doi:10.1186/1746-1340-18-3

Cite this article as: Bronfort et al: Effectiveness of manual therapies: the UK evidence report. Chiropractic \& Osteopathy 2010 18:3.

\section{Submit your next manuscript to BioMed Central and take full advantage of:}

- Convenient online submission

- Thorough peer review

- No space constraints or color figure charges

- Immediate publication on acceptance

- Inclusion in PubMed, CAS, Scopus and Google Scholar

- Research which is freely available for redistribution
Ciomed Central 